\title{
A systematic study of the optical properties of mononuclear hybrid organo-inorganic lanthanoid complexes $\uparrow$
}

\author{
Matias Zapata-Lizama, ${ }^{\text {a,b }}$ Patricio Hermosilla-lbáñez, (DD a,b \\ Diego Venegas-Yazigi, (DD a,b Guillermo Mínguez Espallargas, (D) ${ }^{c}$ \\ Lauro June Queiroz Maia, ${ }^{d}$ Gisane Gasparotto, ${ }^{d}$ Ricardo Costa De Santana (D)*d and \\ Walter Cañón-Mancisidor (iD *a,b
}

\begin{abstract}
A series of hybrid organo-inorganic mononuclear lanthanoid complexes, $\left[n-\mathrm{NBu}_{4}\right]_{3}\left[\mathrm{LnH}\left(\mathrm{PW}_{11} \mathrm{O}_{39}\right)\right.$ (phen) $\left.)_{2}\right] \cdot \mathrm{H}_{2} \mathrm{O}$, denoted as $\mathrm{LM}^{4}-1-\mathrm{Ln}\left(\mathrm{Ln}=\mathrm{Dy}{ }^{\prime \prime \prime}, \mathrm{Tb}^{\prime \prime \prime}, \mathrm{Eu}^{\prime \prime \prime \prime}, \mathrm{Nd}^{\prime \prime \prime}, \mathrm{Er}^{\prime \prime \prime}, \mathrm{HO} \mathrm{O}^{\prime \prime \prime}\right.$ and $\left.\mathrm{Gd}^{\prime \prime \prime}\right)$, were synthesized via hydrothermal synthesis and were structurally characterized by X-ray diffraction. The optical properties of all complexes have been investigated in the solid state. The temperature-dependent emission spectra of LM ${ }^{4}$-1-Dy, LM ${ }^{4}-1-T b$ and LM $^{4}-1-E u$ complexes show intense lanthanoid emissions in the visible region, while LM4-1-Nd shows near-infrared (NIR) luminescence. The Eull complex shows typical strong red emissions from the ${ }^{5} D_{0} \rightarrow{ }^{7} F_{0,1,2,3,4}$ transitions, with the CIE colour coordinates $(0.631,0.364)$, the colour purity value of $83.9 \%$ and a quantum yield of up to $4.3 \%$, suggesting that the organic fragment has an effect on the optical properties compared to fully inorganic systems, making this complex very attractive as a red component of light-emitting diodes. The luminescence decays of $\mathbf{L M}^{\mathbf{4}} \mathbf{- 1}-\mathbf{D y}$, LM $\mathbf{M}^{\mathbf{4}}-\mathbf{1}-\mathrm{Tb}$ and $\mathbf{L M}^{\mathbf{4}}$ 1-Eu exhibit a biexponential behaviour, with $\tau_{\mathrm{AV}}=4.1(7) \mu \mathrm{s}, 0.35(2) \mathrm{ms}$ and 0.94(3) $\mathrm{ms}$, respectively. The values obtained for Judd-Ofelt intensity parameters $\Omega_{2}$ and $\Omega_{4}$ support the interaction between the Eu ${ }^{\prime \prime \prime}$ and the ligands. Furthermore, those with $\mathrm{Er}^{\prime \prime \prime}$ and $\mathrm{Ho}^{\prime \prime \prime}$ present weak emissions in the visible region. The T-dependent photoluminescence results show that the LM ${ }^{4}-1-D y, ~ L M M^{4}-1-T b$ and LM $^{4}-1-N d$ complexes have good temperature sensitivity, demonstrating that the materials have the potential to be used as a sensing element for luminescent thermometers in different temperature ranges.
\end{abstract}

\section{Introduction}

Temperature-sensitive luminescent molecules have potential applications as optical thermo-sensors for electronic devices, and for medical and biological applications., ${ }^{1,2}$ Various thermo-sensing luminescent molecules like organic dyes, ${ }^{3}$ metal complexes, polymers and extended systems like metal organic frameworks (MOFs) have been reported. ${ }^{4}$

\footnotetext{
${ }^{a}$ Facultad de Química y Biología, Depto. de Química de los Materiales, Universidad de Santiago de Chile, USACH, Chile. E-mail: walter.canon@usach.cl

${ }^{b}$ Centre for the Development of Nanoscience and Nanotechnology, CEDENNA, Chile ${ }^{c}$ Instituto de Ciencia Molecular (ICMol), Universidad de Valencia, Paterna, Spain

${ }^{d}$ Instituto de Física, Universidade Federal de Goiás, Goiânia, GO, Brazil.

E-mail: santana@ufg.br, ricosta.santana@gmail.com

$\dagger$ Electronic supplementary information (ESI) available: Additional figures, schemes and tables and X-ray crystallographic file in CIF format for compounds $\mathbf{L M}^{\mathbf{4}}$-1-Tb, $\mathbf{L M}^{\mathbf{4}} \mathbf{- 1}-\mathbf{E u}, \mathbf{L M}^{\mathbf{4}}-\mathbf{1}-\mathbf{N d}$ and $\mathbf{L M}^{\mathbf{4}}$-1-Ho. The X-Ray crystallographic data for $\mathbf{L} \mathbf{M}^{\mathbf{4}}$-1-Dy, $\mathbf{L} \mathbf{M}^{\mathbf{4}}$-1-Er and $\mathbf{L} \mathbf{M}^{\mathbf{4}} \mathbf{- 1}-\mathbf{G d}$ have been previously reported (see ref. 27). CCDC 1951517 for $\mathbf{L M}^{\mathbf{4}} \mathbf{- 1}-\mathbf{T b}, 1962564$ for $\mathbf{L M}^{\mathbf{4}} \mathbf{- 1}-\mathbf{E u}, 1962563$ for $\mathbf{L M}^{\mathbf{4}} \mathbf{- 1}-\mathbf{N d}$ and 1951518 for 1-Ho. For ESI and crystallographic data in CIF or other electronic format see DOI: 10.1039/d0qi00232a
}

Among these types of molecules lanthanoid (Ln) complexes have been considered as ideal materials for these purposes since Ln ions have unique photophysical properties, showing sharp and characteristic transitions in the visible or near-infrared regions and also long excited-state lifetimes. ${ }^{5}$ The plasticity of the coordination chemistry of lanthanoid ions (Ln) allows the design of novel coordination compounds. In this sense Ln complexes based on aromatic organic ligands can work as "antennas" in order to harvest light. The energy is then transferred from the excited state of the ligand onto the metal ion which eventually gives off its characteristic light since the dipole strengths of $\mathrm{f}-\mathrm{f}$ transitions are very small (Laporte forbidden) and the direct excitation into the $4 \mathrm{f}$ excited levels is very rare. ${ }^{5,6}$ Among trivalent lanthanoid ions, $\mathrm{Tb}^{\mathrm{III}}, \mathrm{Eu}^{\mathrm{III}}$ and $\mathrm{Dy}{ }^{\mathrm{III}}$, generally, present intense green, red and blue emissions respectively, being used as emitters in white light-emitting diodes (WLED), as luminescent probes in the investigation of biochemical systems, and as red activators in X-ray detection materials among others. ${ }^{7-10}$

Moreover, inorganic ligands like polyoxometalates (POMs) have been also used in order to obtain Ln coordination com- 
pounds. ${ }^{11}$ Polyoxometalates (POMs) are metal-oxygen clusters of zero dimensionality, presenting characteristic architectures and various compositions as well as having potential applications in materials science. ${ }^{12}$ These molecules can be used as multidentate inorganic ligands, especially for tungsten lacunary POMs (LPOMs) with defined vacancies having also various sizes, shapes, solubility, flexible coordination sites and modes. ${ }^{13,14}$ These inorganic ligands have also shown properties of harvesting light like organic ones. In these systems, it is possible to observe that the luminescence intensity can be very low, suggesting that the excitation energy of the $\mathrm{O} \rightarrow \mathrm{W}$ charge transfer band of this compound can be quenched by non-radiative transitions within the LPOM. ${ }^{15}$

The combination of conjugated organic and inorganic ligands (LPOMs) with lanthanoid centres can generate hybrid organic-inorganic Ln complexes. This can afford species usually forming dinuclear and/or polynuclear complexes with two different routes for sensitizing the lanthanoid luminescence (the organic and inorganic ones). ${ }^{16-21}$ Many of the systems reported in the literature show that in general in polynuclear systems the coordination sphere of the Ln ion has low symmetry and its coordination sphere is completed by $\mathrm{H}_{2} \mathrm{O}$ molecules, quenching the emission properties. ${ }^{21}$ Moreover, this hybrid organic-inorganic molecule can have potential applications such as magneto-optical devices, optoelectronics, optical markers, laser materials, catalysts and others. ${ }^{5,6,22-26}$

So, high symmetry mononuclear systems with no water molecules are necessary in order to obtain good optical properties in Ln complexes. Despite the exquisite control of coordination chemistry, the preparation of mononuclear hybrid organo-inorganic Ln complexes has remained elusive. These hybrid materials could be benefitted from the combination of the flexibility of organic ligands with the robustness of the LPOM inorganic moieties. ${ }^{27}$

In this work the optical properties (UV-Vis-NIR absorption, excitation, emission and lifetime) in the solid state of the isostructural family of hybrid organo-inorganic Ln complexes $\left(\mathbf{L M}^{4}\right.$-1-Lnt) , where $\mathrm{Ln}=\mathrm{Dy}^{\mathrm{III}}, \mathrm{Tb}^{\mathrm{III}}, \mathrm{Eu}^{\mathrm{III}}, \mathrm{Nd}^{\mathrm{III}}, \mathrm{Er}^{\mathrm{III}}, \mathrm{Ho}^{\mathrm{III}}$ and $\mathrm{Gd}^{\mathrm{III}}$, are presented).

\section{Results and discussion}

\section{Structural characterization}

The preparation of mononuclear hybrid organic-inorganic Ln complexes is not a simple task, dinuclear or polynuclear systems being the published ones. ${ }^{28-30}$

These compounds were obtained by hydrothermal synthesis at $160{ }^{\circ} \mathrm{C}$ for $48 \mathrm{~h}$, giving single crystals of $\left[n-\mathrm{NBu}_{4}\right]_{3}[\mathrm{LnH}$ $\left.\left(\mathrm{PW}_{11} \mathrm{O}_{39}\right)(\text { phen })_{2}\right] \cdot \mathrm{H}_{2} \mathrm{O}\left(\mathrm{Ln}^{\mathrm{III}}=\mathrm{Dy}^{\mathrm{III}}\left(\mathbf{L M}^{4}-\mathbf{1}-\mathrm{Dy}\right), \mathrm{Tb}^{\mathrm{III}}\left(\mathbf{L M}^{\mathbf{4}}-\mathbf{1}-\right.\right.$ Tb), $\quad \operatorname{Eu}^{\mathrm{III}}\left(\mathbf{L M}^{4}-\mathbf{1}-\mathbf{E u}\right), \quad \mathrm{Nd}^{\mathrm{III}}\left(\mathbf{L M}^{4}-\mathbf{1}-\mathbf{N d}\right), \quad \operatorname{Er}^{\mathrm{III}}\left(\mathbf{L M}^{4}-\mathbf{1}-\mathbf{E r}\right)$, $\mathrm{Ho}^{\mathrm{III}}\left(\mathbf{L M}^{\mathbf{4}} \mathbf{- 1}-\mathbf{H o}\right)$ and $\mathrm{Gd}^{\mathrm{III}}\left(\mathbf{L M}^{\mathbf{4}} \mathbf{- 1}-\mathbf{G d}\right)$ suitable for X-ray diffraction (see section S1 to S2, Fig. S1 and Table S1†). These com-

$\$ \mathrm{LM}^{4}=$ Laboratory of molecular magnetism and molecular materials. pounds are all isostructural, crystallizing in the monoclinic $P 2_{1} / c$ space group (see section S3 and Table S2 $\dagger$ ). Electroneutrality is achieved by three $\left[n-\mathrm{NBu}_{4}\right]^{+}$cations that exist in the crystal lattice, and by one proton that is delocalized over the oxygen atoms of the LPOM. ${ }^{31}$ A complex of the formula $\left[\mathrm{LnH}\left(\mathrm{PW}_{11} \mathrm{O}_{39}\right)(\mathrm{phen})_{2}\right]^{3-}$ is formed by two types of ligands, one inorganic and two organic, forming an octacoordinated complex (Fig. 1). The organic ligands correspond to two phenanthroline molecules and the inorganic one corresponds to the Keggin lacunary polyoxotungstate $\left(\left[\mathrm{PW}_{11} \mathrm{O}_{39}\right]^{7-}\right)$. The importance of having a lacunary POM is that it has a rigid crystal field around the lanthanoid cation, in contrast to the more flexible organic ligands being also softer than the POM from the HSAB point of view. The distances between the Ln and the nitrogen atoms of the phenanthrolines are in the range of $2.545(14)$ to $2.646(16) \AA$, whereas the distances between the Ln to oxygen atoms of the $\left[\mathrm{PW}_{11} \mathrm{O}_{39}\right]^{7-}$ are in the 2.225(14) to 2.358(11) ̊ range.

The compounds are arranged in the crystal packing by $\pi-\pi$ stacking between the aromatic rings ( 220 C17 C18 C19 C23 C24; N40 C37 C38 C39 C43 C44) of the phenanthroline ligands, forming pairs with distances ranging from $3.568 \AA$ to $3.108 \AA$, for the studied complexes (Fig. S2 $\dagger$ ). The distance between two molecules in each pair (Ln-Ln) is 9.714(1) $\AA$,

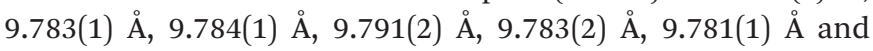

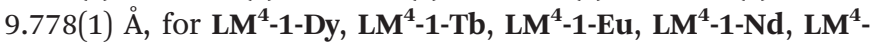
1-Er, $\mathbf{L M}^{\mathbf{4}}$-1-Ho and $\mathbf{L M}^{\mathbf{4}}$-1-Gd complexes, respectively.

Continuous shape measurement (CShMs) calculations done using the SHAPE code $e^{32,33}$ reveal that the geometry of the Ln complexes can be described as a square antiprism (sa), thus implying that the Ln centres present a pseudo- $D_{4 \mathrm{~d}}$ symmetry (Fig. S3†). This type of geometry is very common since most $\mathrm{Ln}^{\mathrm{III}}$ complexes with octacoordinated geometries present square antiprism, or triangular dodecahedron or bicapped trigonal prism types of geometries. ${ }^{34-38}$ Reported data show that the metal centres of the fully inorganic ligand systems of

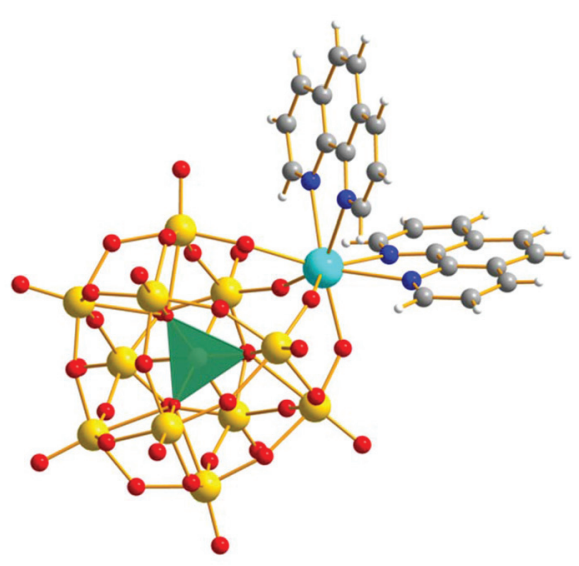

Fig. 1 Ball-and-stick representation of hybrid organic-inorganic molecular complexes $\left[\mathrm{LnH}\left(\mathrm{PW}_{11} \mathrm{O}_{39}\right)(\text { phen })_{2}\right]^{3-}$. Water molecule and $\left[n-\mathrm{NBu}_{4}\right]^{+}$cations are omitted for clarity. Colour label: Ln (cyan), W (yellow), N (blue), C (grey) O (red) and P (green). 
$\left[\mathrm{Ln}\left(\mathrm{PW}_{11} \mathrm{O}_{39}\right)_{2}\right]^{11-}$ and $\left[\mathrm{Ln}\left(\mathrm{SiW}_{11} \mathrm{O}_{39}\right)_{2}\right]^{13-}$ present a square antiprism geometry, ${ }^{31}$ also observed for the systems presented in this work.

Finally, the XRPD pattern of $\mathbf{L M}^{\mathbf{4}} \mathbf{- 1}-\mathbf{L n}$ is quite similar for all the Ln complexes, but some slight differences in some intensities exist, which are due to the textural problems of the material. The crystalline products are isostructural and also are in agreement with their simulated patterns, demonstrating that the crystal structures of the compounds are truly representative of the bulk materials (Fig. S4 and S5†).

\section{Electronic spectra}

The solid-state UV-Vis-NIR spectra of the $\mathbf{L M}^{\mathbf{4}}$-1-Ln complexes collected at room temperature are depicted in Fig. S6. $\dagger$ All $\mathbf{L M}^{\mathbf{4}}$-1-Ln complexes do not have water molecules in the first coordination sphere of the $\mathrm{Ln}^{\mathrm{III}}$ ion.

The absorption spectrum of $\mathbf{L} \mathbf{M}^{\mathbf{4}}$-1-Dy shows typical bands for $\mathrm{Dy}^{\mathrm{III}}$ attributed to the transitions from the ${ }^{6} \mathrm{H}_{15 / 2}$ ground state to the ${ }^{6} \mathrm{~F}_{3 / 2},{ }^{6} \mathrm{~F}_{5 / 2},{ }^{6} \mathrm{~F}_{7 / 2},{ }^{6} \mathrm{H}_{7 / 2},{ }^{6} \mathrm{H}_{9 / 2}$ and ${ }^{6} \mathrm{H}_{11 / 2}$ excited states respectively, due to the electronic transitions of trivalent dysprosium with the $4 \mathrm{f}^{9}$ intra configuration (Fig. S6a $\dagger$ ). ${ }^{39}$

The UV-Vis-NIR spectrum of the $\mathbf{L M}^{\mathbf{4}} \mathbf{- 1 - T b}$ complex is depicted in Fig. S6b, $\uparrow$ where only one band could be observed in the whole spectral range and due to the ${ }^{7} \mathrm{~F}_{6} \rightarrow{ }^{7} \mathrm{~F}_{0}$ transition at $1694 \mathrm{~nm}$.

The spectrum of $\mathbf{L M}^{\mathbf{4}}$-1-Eu, Fig. S6c, $\dagger$ taken from 350 to $850 \mathrm{~nm}$, shows characteristic absorption lines assigned to the ${ }^{7} \mathrm{~F}_{0} \rightarrow{ }^{5} \mathrm{D}_{0,1,2}$ and ${ }^{7} \mathrm{~F}_{0} \rightarrow{ }^{5} \mathrm{~L}_{6}$ transitions at 590, 540, 511 and $385 \mathrm{~nm}$ respectively. ${ }^{40}$ A small peak at $2075 \mathrm{~nm}$ is attributed to the ${ }^{7} \mathrm{~F}_{0} \rightarrow{ }^{7} \mathrm{~F}_{6}$ transition. Several absorptions associated with the overtones of $\mathrm{OH}$ of the $\mathrm{POM}$ and $\mathrm{CH}$ of the phenanthroline appear at 747 and 804, 1950, 2150 and $2280 \mathrm{~nm}$.

Fig. S6d $\dagger$ shows the absorption spectrum of $\mathbf{L M}^{\mathbf{4}} \mathbf{- 1 - N d}$; several sharp bands can be observed in the 400-850 $\mathrm{nm}$ range, each one corresponding to the transitions from the ${ }^{4} I_{9 / 2}$ ground state to the excite states ${ }^{4} \mathrm{~F}_{3 / 2},\left({ }^{4} \mathrm{~F}_{5 / 2},{ }^{2} \mathrm{H}_{9 / 2}\right),{ }^{4} \mathrm{~F}_{7 / 2},{ }^{4} \mathrm{~S}_{3 / 2}$, ${ }^{4} \mathrm{~F}_{9 / 2},{ }^{4} \mathrm{~F}_{3 / 2},{ }^{2} \mathrm{H}_{11 / 2},{ }^{4} \mathrm{G}_{5 / 2},{ }^{2} \mathrm{G}_{7 / 2},{ }^{4} \mathrm{G}_{7 / 2},{ }^{4} \mathrm{G}_{9 / 2},\left({ }^{2} \mathrm{D}_{3 / 2},{ }^{2} \mathrm{G}_{9 / 2}\right),{ }^{4} \mathrm{G}_{11 / 2}$ and ${ }^{2} \mathrm{P}_{1 / 2}{ }^{41}$ The band positions are in good agreement with those of other $\mathrm{Nd}^{\mathrm{III}}$ polyoxometalate complexes. ${ }^{42}$

For the $\mathbf{L M}^{\mathbf{4}}$-1-Er complex, the UV-Vis spectrum, Fig. S6e, $\dagger$ shows a number of spectral bands corresponding to the transitions between the ${ }^{4} \mathrm{I}_{15 / 2}$ ground state and the ${ }^{4} \mathrm{I}_{9 / 2},{ }^{4} \mathrm{~F}_{9 / 2},{ }^{4} \mathrm{~S}_{3 / 2}$, ${ }^{4} \mathrm{~F}_{7 / 2},{ }^{4} \mathrm{~F}_{5 / 2},\left({ }^{4} \mathrm{G},{ }^{4} \mathrm{~F},{ }^{2} \mathrm{H}\right)_{9 / 2}$ and ${ }^{4} \mathrm{G}_{11 / 2}$ excited states. ${ }^{43}$

The absorption spectrum for the $\mathbf{L M}^{\mathbf{4}} \mathbf{- 1}-\mathbf{H o}$ complex is presented in Fig. S6f, $\uparrow$ and the observed transitions from the ${ }^{5} \mathrm{I}_{8}$ ground state to the ${ }^{2 \mathrm{~S}+1} \mathrm{~L}_{J}$ excited states ${ }^{5} \mathrm{~F}_{5},\left({ }^{5} \mathrm{~F}_{4},{ }^{5} \mathrm{~S}_{2}\right),{ }^{5} \mathrm{~F}_{3},\left({ }^{5} \mathrm{~F}_{2}\right.$, $\left.{ }^{3} \mathrm{~K}_{8}\right),\left({ }^{5} \mathrm{~F}_{1},{ }^{5} \mathrm{G}_{6}\right)$ and ${ }^{5} \mathrm{G}_{5} \cdot{ }^{44}$

Fig. $\mathrm{S} 7 \dagger$ shows the room temperature solid state absorption spectra of both free ligands, the inorganic $\left(\left[\mathrm{PW}_{11} \mathrm{O}_{39} \mathrm{H}_{3}\right]^{4-}\right)$ and the phenanthroline and also of the $\mathbf{L M}^{\mathbf{4}} \mathbf{- 1 - G d}$ complex. Fig. S7a and $\mathrm{b}_{\dagger} \dagger$ correspond to the absorption spectra of the $\left[\mathrm{PW}_{11} \mathrm{O}_{39} \mathrm{H}_{3}\right]^{4-}$ ligand, taken in the UV-Vis region (200-500 nm), showing a broad band with a prominent shoulder at $\sim 250 \mathrm{~nm}$, which can be associated with the oxygen to metal (W) charge transfer. The spectrum of the phenanthroline (Fig. S7c $\dagger$ ) ligand shows a broad absorption band in the
200-450 nm range, with a series of shoulders at 225, 275, 290 and $345 \mathrm{~nm}$, as reported by Linnell and Kaczmarczyk. ${ }^{45}$

The absorption spectrum of $\mathbf{L M}^{\mathbf{4}} \mathbf{- 1 - G d}$ shown in Fig. S7d $\dagger$ consists of a broad absorption, in which three intense bands are observed: 250, 290 and $345 \mathrm{~nm}$. The first band can be associated with the $\left[\mathrm{PW}_{11} \mathrm{O}_{39}\right]^{7-}$ unit and the other two must correspond to the phenanthroline ligand, as observed in the spectra of free 1,10-phenanthroline. As the $\mathrm{Gd}^{\mathrm{III}}$ ion does not present any absorption below $311 \mathrm{~nm}$, the $\mathbf{L M}^{\mathbf{4}} \mathbf{- 1}-\mathbf{G d}$ complex will be used to investigate any charge transfer processes between both ligands (1,10-phenanthroline and LPOM) to the emitting levels of $\mathrm{Dy}^{\mathrm{III}}, \mathrm{Eu}^{\mathrm{III}}$ and $\mathrm{Tb}^{\mathrm{III}}$ ions. In the UV region (below $380 \mathrm{~nm}$ ) no $\mathrm{f}-\mathrm{f}$ transitions were observed for all studied compounds.

\section{Photoluminescence results}

Solid-state emission spectra for all $\mathbf{L M}^{\mathbf{4}}$-1-Ln complexes have been collected at room temperature in the visible and IR regions. The results confirm that the antenna effect is observed for all compounds. The results for $\mathbf{L} \mathbf{M}^{\mathbf{4}} \mathbf{- 1 - G d}$ will be used to determine the singlet and triplet state of the ligand for the analysis of the energy transfer (see ESI, Fig. S8 $\dagger$ ). For compounds $\mathbf{L} \mathbf{M}^{\mathbf{4}}$-1-Dy, $\mathbf{L} \mathbf{M}^{\mathbf{4}}-\mathbf{1 - T b}, \quad \mathbf{L} \mathbf{M}^{\mathbf{4}}-\mathbf{1}-\mathbf{E u}$ and $\mathbf{L} \mathbf{M}^{\mathbf{4}}-\mathbf{1 - N d}$ the intensity profiles associated with each compound were observed with different excitation energies all of them in the range, in which both ligands absorb. Finally, the excitation energy used is the one that provides more intense emissions in each case (see Fig. S9†).

The emission spectra of $\left[\mathrm{NBu}_{4}\right]_{4}\left[\mathrm{PW}_{11} \mathrm{O}_{39} \mathrm{H}_{3}\right]$ and 1,10-phenanthroline were obtained at room temperature, Fig. S10. $\dagger$ The experimental measurements are in agreement with previously reported data, in which the observed emission of 1,10-phenantroline is in the range of $380 \mathrm{~nm}$ to $500 \mathrm{~nm},{ }^{46}$ and for the $\left[\mathrm{PW}_{11} \mathrm{O}_{39}\right]^{7-}$ anion the emission is in the same spectral range. ${ }^{47}$ The results show that the organic ligand has a more intense signal compared to the LPOM one, suggesting that the transition between the $S_{0}$ and $S_{1}$ energy levels of the organic ligand is more predominant compared to the ${ }^{3} \mathrm{~T}_{1 \mathrm{u}} \rightarrow{ }^{1} \mathrm{~A}_{1 \mathrm{~g}}$ transition of the LPOM fragment. However, both ligands contribute to the antenna effect.

\section{LM ${ }^{4}$-1-Dy}

The excitation and emission spectra of the $\mathbf{L M}^{\mathbf{4}}$-1-Dy compound are shown in Fig. 2. The excitation spectra, Fig. 2a, monitoring the emission corresponding the ${ }^{4} \mathrm{~F}_{9 / 2} \rightarrow{ }^{6} \mathrm{H}_{13 / 2}$ transition at $573 \mathrm{~nm}$, consist of an intense band centred at $352 \mathrm{~nm}$ attributed to the transition between the $S_{0}$ and $S_{1}$ energy levels of the phen ligand with the $\pi-\pi^{*}$ character; Dy ${ }^{\text {II }}$ does not show absorption bands in this region. In Fig. $2 b$ the temperature dependence of the emission spectra from 15 to $300 \mathrm{~K}$ is shown, in which the intensities of the bands are normalized to the ${ }^{4} \mathrm{~F}_{9 / 2} \rightarrow{ }^{6} \mathrm{H}_{13 / 2}$ transition and obtained under excitation at $352 \mathrm{~nm}$. All the spectra consist of three bands at 479, 571 and $658 \mathrm{~nm}$ assigned to the ${ }^{4} \mathrm{~F}_{9 / 2} \rightarrow{ }^{6} \mathrm{H}_{15 / 2}$ (blue, B), ${ }^{4} \mathrm{~F}_{9 / 2} \rightarrow{ }^{6} \mathrm{H}_{13 / 2}$ (yellow, Y) and ${ }^{4} \mathrm{~F}_{9 / 2} \rightarrow{ }^{6} \mathrm{H}_{11 / 2}$ transitions, respectively. All the emission line energies are independent of 

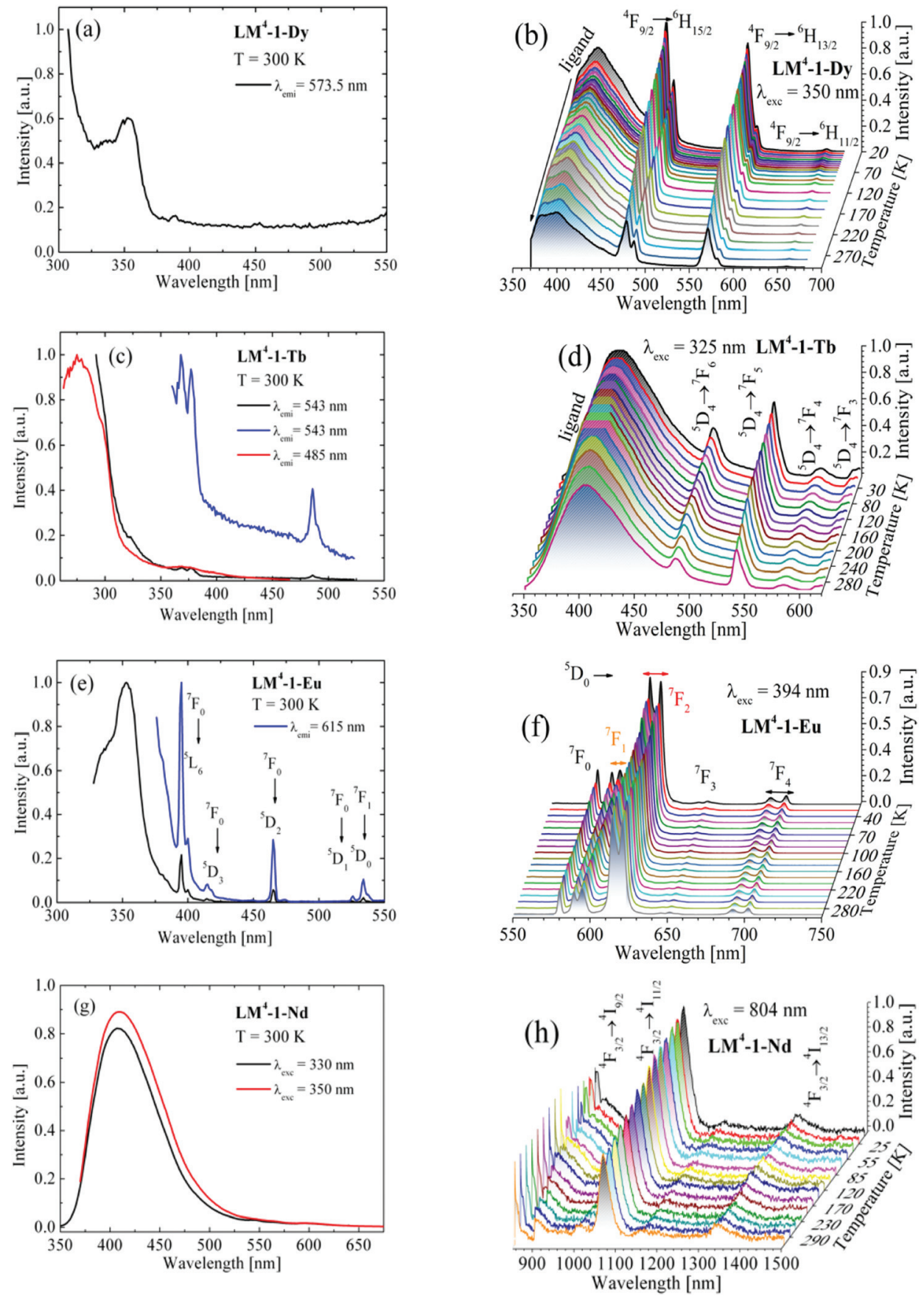

Fig. 2 Excitation spectra: (a) $L M^{4}$-1-Dy by monitoring the ${ }^{4} \mathrm{~F}_{9 / 2} \rightarrow{ }^{6} \mathrm{H}_{13 / 2}$ transition at $573 \mathrm{~nm}$, (c) $\mathrm{LM}^{4}-1-\mathrm{Tb}$ by monitoring the ${ }^{5} \mathrm{D}_{4} \rightarrow{ }^{7} \mathrm{~F}_{5}$ and ${ }^{5} \mathrm{D}_{4} \rightarrow$ ${ }^{7} \mathrm{~F}_{6}$ transitions at 543 and $485 \mathrm{~nm}$ and (e) excitation spectrum of the LM ${ }^{4}-1$-Eu complex by monitoring the ${ }^{5} \mathrm{D}_{0} \rightarrow{ }^{7} \mathrm{~F}_{2}$ transition at $615 \mathrm{~nm}$. Emission spectra: thermal dependency of the emission spectrum for (b) LM L $^{4}-1-D y$ (d) LM L $^{4}-1-T b$ and (f) LM L $^{4}-1-E u$ under excitation at 350,325 and 394 nm, respectively. The emission spectra of $\mathrm{LM}^{4}-1-\mathrm{Nd}$ at room temperature under excitation at 330 and $350 \mathrm{~nm}$ are shown in $(\mathrm{g})$ and the temperature dependence of the emission spectra under $804 \mathrm{~nm}$ excitation is shown in (h).

the temperature; the ${ }^{4} \mathrm{~F}_{9 / 2} \rightarrow{ }^{6} \mathrm{H}_{15 / 2}$ and ${ }^{4} \mathrm{~F}_{9 / 2} \rightarrow{ }^{6} \mathrm{H}_{11 / 2}$ transitions are the highest and less intense bands, respectively. No change in the position of the Dy ${ }^{\mathrm{III}}$ transitions is observed in the whole temperature range. Also, one intense and broad band can be observed centred at $\sim 390 \mathrm{~nm}$ attributed to both ligands, as mentioned above (Fig. S10 $\dagger$ ), which becomes less intense with the increasing temperature. The $\mathbf{B}$ transition has a magnetic dipole (MD) nature being less affected by the site symmetry, in contrast to the hypersensitive $\mathbf{Y}$ transition, which has an electric dipole (ED) nature that is strongly influenced by the local environment. ${ }^{48}$ The $\mathbf{Y} / \mathbf{B}$ intensity ratio for Dy ${ }^{\mathrm{III}}$ can give information about the strength of the covalent/ionic bonding character between the Dy ${ }^{\mathrm{II}}$ and the atoms of the first coordination sphere, and the asymmetry of the site occupied 
by the lanthanoid ion. ${ }^{49}$ The temperature dependence of the $\mathbf{Y} / \mathbf{B}$ intensity ratio, obtained from the experimental spectra, is nearly independent of temperature as shown in Fig. S11a, $\dagger \mathbf{Y} / \mathbf{B}$ $\approx 0.63(6)$; this result is associated with the fact of the ${ }^{4} \mathrm{~F}_{9 / 2} \rightarrow$ ${ }^{6} \mathrm{H}_{15 / 2}$ transition is more intense than the ${ }^{4} \mathrm{~F}_{9 / 2} \rightarrow{ }^{6} \mathrm{H}_{13 / 2}$ transition, suggesting a more covalent character of the bonding between the atoms of the first coordination sphere and the Dy $^{\text {III }}$ ion. ${ }^{50}$

\section{$L M^{4}-1-T b$}

The excitation spectra of the $\mathbf{L} \mathbf{M}^{\mathbf{4}}-\mathbf{1 - T b}$ compound were acquired by monitoring the emissions at 543 and $485 \mathrm{~nm}$, corresponding to the ${ }^{5} \mathrm{D}_{4} \rightarrow{ }^{7} \mathrm{~F}_{5}$ and ${ }^{5} \mathrm{D}_{4} \rightarrow{ }^{7} \mathrm{~F}_{6}$ transitions, respectively (Fig. 2c). The broad absorption band at $\sim 276 \mathrm{~nm}$, by monitoring the emission at $485 \mathrm{~nm}$, is assigned to the $\pi-\pi^{*}$ transition of the ligands, being much more intense than those attributed to the $\mathrm{Tb}^{\mathrm{III}}$ absorptions. In addition, the two peaks at 368 and $377 \mathrm{~nm}$ are due the ${ }^{5} \mathrm{~L}_{10} \rightarrow{ }^{5} \mathrm{D}_{4}$ absorption. The presence of the broad band indicates the existence of the energy transfer from both ligands to the energy levels of the $\mathrm{Tb}^{\mathrm{III}}$ ion.

The emission spectra of the $\mathrm{Tb}^{\mathrm{III}}$ compound as a function of temperature, Fig. 2d, show typical emission bands corresponding to ${ }^{5} \mathrm{D}_{4} \rightarrow{ }^{7} \mathrm{~F}_{6}$ (blue, B) at $486 \mathrm{~nm},{ }^{5} \mathrm{D}_{4} \rightarrow{ }^{7} \mathrm{~F}_{5}$ (green, G) at $543 \mathrm{~nm},{ }^{5} \mathrm{D}_{4} \rightarrow{ }^{7} \mathrm{~F}_{4}(586 \mathrm{~nm})$ and ${ }^{5} \mathrm{D}_{4} \rightarrow{ }^{7} \mathrm{~F}_{3}(618 \mathrm{~nm}) \mathrm{f}-\mathrm{f}$ transitions of $\mathrm{Tb}^{\mathrm{III}}$ ions as a function of the temperature from 15 to $300 \mathrm{~K}$. The spectra also present a rather broad and intense emission in the $340-450 \mathrm{~nm}$ region attributed to the phen and LPOM ligand, as observed for $\mathbf{L M}^{\mathbf{4}} \mathbf{- 1}$-Dy. No change in the position of the $\mathrm{Tb}^{\mathrm{III}}$ transitions is observed in the entire temperature range. Among all transitions, the ${ }^{5} \mathrm{D}_{4} \rightarrow{ }^{7} \mathrm{~F}_{5}$ transition has a magnetic dipole (MD) character, being dominant over the others indicating that $\mathrm{Tb}^{\mathrm{III}}$ ions can emit green light when excited with UV light. The $\mathrm{Tb}^{\mathrm{III}} \mathbf{G} / \mathbf{B}$ ratio, as well as the Y/B of Dy ${ }^{\text {III }}$, plays the role describing the covalent/ionic bonding character between the $\mathrm{Tb}^{\mathrm{III}}$ and the first coordination sphere atoms. For $\mathbf{L} \mathbf{M}^{\mathbf{4}} \mathbf{- 1}-\mathbf{T b}$, the dependence of the $\mathbf{G} / \mathbf{B}$ ratio as a function of temperature has a mean value of $\sim 1.9$ in the whole temperature range and it is depicted in Fig. S11b. $\dagger$

\section{LM ${ }^{4}$-1-Eu}

The excitation spectrum of $\mathbf{L M}^{\mathbf{4}}$-1-Eu (Fig. 2e) was acquired monitoring the hypersensitive ${ }^{5} \mathrm{D}_{0} \rightarrow{ }^{7} \mathrm{~F}_{2}$ Eu ${ }^{\text {III }}$ transition at $615 \mathrm{~nm}$ at room temperature, and it is possible to identify the characteristic bands related to Eu ${ }^{\mathrm{III}}$ excited states at $395 \mathrm{~nm}$ $\left({ }^{7} \mathrm{~F}_{0} \rightarrow{ }^{5} \mathrm{~L}_{6}\right), 414 \mathrm{~nm}\left({ }^{7} \mathrm{~F}_{0} \rightarrow{ }^{5} \mathrm{D}_{3}\right), 465 \mathrm{~nm}\left({ }^{7} \mathrm{~F}_{0} \rightarrow{ }^{5} \mathrm{D}_{2}\right), 525 \mathrm{~nm}$ $\left({ }^{7} \mathrm{~F}_{0} \rightarrow{ }^{5} \mathrm{D}_{1}\right)$ and $535 \mathrm{~nm}\left({ }^{7} \mathrm{~F}_{1} \rightarrow{ }^{5} \mathrm{D}_{0}\right)$, in good agreement with the absorption spectra. In addition, one broad band centred at $352 \mathrm{~nm}$ is observed and assigned as a MLCT from the $\mathrm{Eu}^{\mathrm{III}}$ to both ligands (phen and LPOM). The emission spectra under excitation at $394 \mathrm{~nm}$ at different temperatures are given in Fig. 2f, showing the characteristic emission bands of Eu ${ }^{\text {III }}$, being the first one centred at $579 \mathrm{~nm}$ corresponding to the ${ }^{5} \mathrm{D}_{0}$ $\rightarrow{ }^{7} \mathrm{~F}_{0}$ transition, and the second one at 593 (orange, $\mathbf{O}$ ) $\mathrm{nm}$ is the ${ }^{5} \mathrm{D}_{0} \rightarrow{ }^{7} \mathrm{~F}_{1}$ transition, which has a magnetic dipole (MD) nature and it is known to be less affected by the site symmetry.
The third one is the most intense transition, centred at $614 \mathrm{~nm}$ (red, $\mathbf{R},{ }^{5} \mathrm{D}_{0} \rightarrow{ }^{7} \mathrm{~F}_{2}$ ), being a hypersensitive electric dipole (ED) transition that is strongly influenced by the local environment. ${ }^{51,52}$ Weak $\mathrm{Eu}^{\mathrm{III}}$ emissions can also be observed at 652 and $697 \mathrm{~nm}$, due to the ${ }^{5} \mathrm{D}_{0} \rightarrow{ }^{7} \mathrm{~F}_{3}$ and ${ }^{5} \mathrm{D}_{0} \rightarrow{ }^{7} \mathrm{~F}_{4}$ transitions, respectively. Also, a broad and less intense band can be observed to be centred around $440 \mathrm{~nm}$ due to the excitation of both ligands (Fig. S10 $\dagger$ ). The presence of a single line of the ${ }^{5} \mathrm{D}_{0} \rightarrow{ }^{7} \mathrm{~F}_{0}$ transition is an indication that the $\mathrm{Eu}^{\mathrm{III}}$ ions occupy one single site symmetry without an inversion centre, ${ }^{19,53}$ in agreement with the structural results. Note that all ${ }^{5} \mathrm{D}_{0} \rightarrow$ ${ }^{7} \mathrm{~F}_{1,2,3,4}$ split into doublets (Fig. 2f), Stark splitting, indicating that Eu ${ }^{\text {III }}$ ions occupy a low site symmetry. ${ }^{51}$ The ${ }^{5} \mathrm{D}_{0} \rightarrow{ }^{7} \mathrm{~F}_{6}$ transition does not appear in the spectrum due to the experimental conditions, being out of the range of the detector. No changes in the barycentre position of each $\mathrm{Eu}^{\mathrm{III}}$ transition are observed in the whole temperature range. The ratio of the integrated areas of the ${ }^{5} \mathrm{D}_{0} \rightarrow{ }^{7} \mathrm{~F}_{2}(\mathbf{R})$ and ${ }^{5} \mathrm{D}_{0} \rightarrow{ }^{7} \mathrm{~F}_{1}(\mathbf{O})$ transitions, $\mathbf{R} / \mathbf{O}=\mathrm{I}\left({ }^{5} \mathrm{D}_{0} \rightarrow{ }^{7} \mathrm{~F}_{2}\right) / \mathrm{I}\left({ }^{5} \mathrm{D}_{0} \rightarrow{ }^{7} \mathrm{~F}_{1}\right)$, provides the same information as $\mathbf{Y} / \mathbf{B}$ for Dy ${ }^{\mathrm{III}}$. The $\mathbf{R} / \mathbf{O}$ values are nearly independent of temperature and range from $4.3(17 \mathrm{~K})$ to $4.5(300 \mathrm{~K})$, Fig. S11c. $\dagger$ This indicates a low degree of covalency between the $\mathrm{Eu}^{\mathrm{III}}$ and the donor atom of the first coordination sphere, with the Eu ${ }^{\mathrm{III}}$ occupying a low symmetry coordination centre. ${ }^{19,49}$ Furthermore, the obtained $\mathbf{Y} / \mathbf{B}, \mathbf{G} / \mathbf{B}$ and $\mathbf{R} / \mathbf{O}$ ratios can be correlated with those obtained in previous results for other Ln-POMs. $^{20,21}$

To obtain more information about the spectral properties of the $\mathrm{Eu}^{\mathrm{III}}$ compound, the experimental intensity $\Omega_{2}$ and $\Omega_{4}$ parameters, the radiative emission rates $\left(\mathrm{A}_{\mathrm{rad}}\right)$, the radiative lifetime $\left(\tau_{\mathrm{rad}}\right)$ and the branching ratios $\beta_{02}$ and $\beta_{04}$ were calculated. This was done by comparing the emission data associated with the ${ }^{5} \mathrm{D}_{0} \rightarrow{ }^{7} \mathrm{~F}_{2}$ and ${ }^{5} \mathrm{D}_{0} \rightarrow{ }^{7} \mathrm{~F}_{4}$ transitions to the $\mathrm{MD}$ transition ${ }^{5} \mathrm{D}_{0} \rightarrow{ }^{7} \mathrm{~F}_{1}$, using a Judd-Ofelt (JO) theory. ${ }^{54,55}$

The JO theory states that the $\Omega_{2}$ intensity parameter is related to the $\mathrm{Ln}^{\mathrm{III}}$ site symmetry and could be interpreted as a consequence of a hypersensitive behaviour of the ${ }^{5} \mathrm{D}_{0} \rightarrow{ }^{7} \mathrm{~F}_{2}$ transition, and that the spontaneous emission probabilities for Eu ${ }^{\text {III }}$ transitions ${ }^{5} \mathrm{D}_{0} \rightarrow{ }^{7} \mathrm{~F}_{0,1,2,3,4}$ could be expressed by the equation: ${ }^{52}$

$$
A\left({ }^{5} \mathrm{D}_{0} \rightarrow{ }^{7} \mathrm{~F}_{J}\right)=\frac{4 e^{2} \omega^{3}}{3 \hbar c^{3}} \frac{n_{0}\left(n_{0}{ }^{2}+2\right)}{9} \sum_{\lambda} \Omega_{\lambda}\left\langle{ }^{7} \mathrm{~F}_{J}\left\|U^{(\lambda)}\right\|^{5} \mathrm{D}_{0}\right\rangle^{2}
$$

where $e$ is the electron charge, $n_{0}$ is the index of refraction of the host, $\omega$ is the frequency of the transition, $\hbar$ is the Planck's constant, $\Omega_{\lambda}$ are the Judd-Ofelt intensity parameters ${ }^{54,55}$ and $\left\langle{ }^{7} \mathrm{~F}_{J}|| U^{(\lambda)}||^{5} \mathrm{D}_{0}\right\rangle^{2}$ is the reduced matrix element for $\lambda=J=0,2$ and 4 , given by Carnall et al. ${ }^{56}$ The total radiative decay rate, $A_{\text {rad }}$, for the particular case involving the $\mathrm{Eu}^{\mathrm{III}}$ ion is written in terms of the integrated area of their emission spectra $I_{0 J}$ as:

$$
A_{\mathrm{rad}}=\frac{A_{01} h c \omega_{01}}{S_{01}} \sum_{J=0}^{6} \frac{I_{0 J}}{h c \omega_{0 J}}
$$


where $A_{01}$ is the spontaneous decay rate for the ${ }^{5} \mathrm{D}_{0} \rightarrow{ }^{7} \mathrm{~F}_{1}$ transition given by $A_{01}=A^{\prime}{ }_{01} n^{3}$ with $A^{\prime}{ }_{01}=14.65 \mathrm{~s}^{-1}$ in a vacuum and $I_{0 J}$ is the area of the emission curves. The intensity parameters $\Omega_{\lambda}$ could be calculated with the relation: ${ }^{6}$

$$
\Omega_{\lambda}=\frac{3 h}{64 \pi^{4} e^{2} \bar{\omega}^{3} c^{3}} \frac{9}{n\left(n^{2}+2\right)} \frac{1}{\left|{ }^{7} \mathrm{~F}_{J} U^{(\lambda)} 5 \mathrm{D}_{0}\right|^{2}} A_{0 J}
$$

with $\lambda=J=0,2$ and 4 . The reduced matrix elements: $\left\langle{ }^{5} \mathrm{D}_{0} \|\right.$ $\left.U^{(\lambda)}||^{7} \mathrm{~F}_{2}\right\rangle^{2}=0.0032$ and $\left\langle{ }^{5} \mathrm{D}_{0} \| U^{(\lambda)}||^{7} \mathrm{~F}_{4}\right\rangle^{2}=0.0023$ were taken from a report by Carnall et al. ${ }^{56}$ The predicted radiative lifetime $\tau_{\text {rad }}$ is given by the inverse of the total area under the emission curves, $\tau_{\text {rad }}=1 / A_{\text {rad }}$, and the branching ratios are given by $\beta_{0 J^{\prime}}=A_{0 J^{\prime}} / A_{\mathrm{rad}}$, with $J^{\prime}=1,2$ or 4 . As the ${ }^{5} \mathrm{D}_{0} \rightarrow{ }^{7} \mathrm{~F}_{6}$ transition was not observed, $\Omega_{6}$ cannot be estimated from the experiment. The evolution of the temperature dependence of the obtained JO intensity parameters $\Omega_{2}$ and $\Omega_{4}$ is shown in Fig. 3. The radiative emission rates $\left(A_{\text {rad }}\right)$, the radiative lifetime $\left(\tau_{\mathrm{rad}}\right)$ and the branching ratios $\beta_{02}$ and $\beta_{04}$ are presented in Fig. S12a and b. $\dagger$ All these parameters are nearly independent of the temperature. In Table 1 some values of these parameters for selected temperatures are summarized, revealing relatively high values of the $\Omega_{2}$ parameter, which tends to $\Omega_{2}>\Omega_{4}$ throughout the temperature range. The large $\Omega_{2}$ values could be associated with the distortion of the site symmetry of the $\mathrm{Eu}^{\mathrm{III}}$ compound (short range effect) and/or moderate covalence of the metal-ligand bonds, ${ }^{57}$ as shown by the crystallographic data. The $\Omega_{2}$ and $\Omega_{4}$ values can be compared with the $\left[\mathrm{Eu}(\mathrm{DPA})_{3}\right]^{3-}(\mathrm{DPA}=$ dipicolinate $)$ complex data: $\Omega_{2}=10.5 \times 10^{-20}$ $\mathrm{cm}^{2}$ and $\Omega_{4}=5.31 \times 10^{-20} \mathrm{~cm}^{2} .{ }^{57}$ The radiative lifetimes $\left(\tau_{\mathrm{rad}}\right)$ of $\mathbf{L} \mathbf{M}^{\mathbf{4}}$-1-Eu are $2.9(3)$ at $17 \mathrm{~K}$ and $2.7(2) \mathrm{ms}$ at $300 \mathrm{~K}$, which

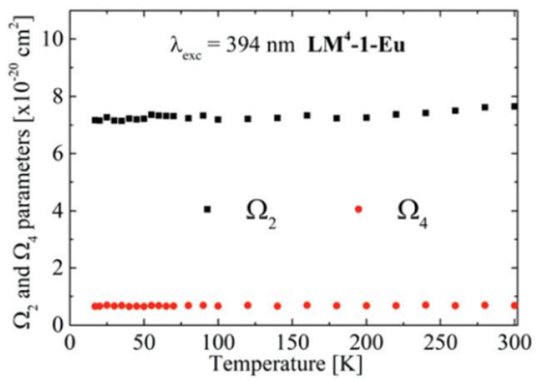

Fig. 3 Judd-Ofelt $\Omega_{2}$ and $\Omega_{4}$ intensity parameters as a function of temperature for $L M^{4}-1-E u$.

Table 1 Radiative decay rates $A_{\text {rad, }}$ lifetime $\tau_{\text {rad }} \Omega_{2}$ and $\Omega_{4}$ Judd-Ofelt parameters and $\beta_{0 J}$ branching ratios for selected temperatures

\section{LM ${ }^{4}$-1-Eu}

\begin{tabular}{llllllll}
\hline $\begin{array}{l}\text { Temp. } \\
{[\mathrm{K}]}\end{array}$ & $\begin{array}{l}A_{\text {rad }} \\
{\left[\mathrm{s}^{-1}\right]}\end{array}$ & $\begin{array}{l}\tau_{\text {rad }} \\
{[\mathrm{ms}]}\end{array}$ & $\begin{array}{l}\Omega_{2} \\
{\left[10^{-20}\right.}\end{array}$ & $\begin{array}{c}\Omega_{4} \\
\left.\mathrm{~cm}^{2}\right]\end{array}$ & $\begin{array}{l}\beta_{01} \\
{[\%]}\end{array}$ & $\beta_{02}$ & $\beta_{04}$ \\
\hline 17 & 344.1 & 2.91 & 7.17 & 0.65 & 18 & 78 & 4 \\
50 & 345.2 & 2.90 & 7.22 & 0.64 & 18 & 78 & 4 \\
140 & 346.6 & 2.89 & 7.25 & 0.66 & 18 & 78 & 4 \\
240 & 353.9 & 2.83 & 7.42 & 0.69 & 17 & 78 & 5 \\
300 & 362.0 & 2.73 & 7.64 & 0.68 & 17 & 79 & 4
\end{tabular}

can be compared with those of the fully organic $\mathrm{Cs}_{3}\left[\mathrm{Eu}(\mathrm{DPA})_{3}\right]$ complex with a $\tau_{\text {rad }}=2.6 \mathrm{~ms}$ and also with several other organic based $\mathrm{Eu}^{\mathrm{III}}$ complexes with benzothiazole-, benzoxazole-, and benzimidazole-pyridine ligands ( 2.7 to $6.8 \mathrm{~ms}) .{ }^{58,59}$ These results suggest that the hybrid organic-inorganic $\mathrm{Eu}^{\mathrm{III}}$ complex has a similar luminescence efficiency compared to the organic $\mathrm{Eu}^{\mathrm{III}}$ complexes. Analysing the $\beta_{0 J^{\prime}}$ branching ratios (see Fig. S12b $\dagger$ ), $\beta_{01}=17 \%, \beta_{02}=79 \%$ and $\beta_{04}=4 \%(300 \mathrm{~K})$, follow the order of relative intensities ${ }^{5} \mathrm{D}_{0} \rightarrow{ }^{7} \mathrm{~F}_{2}>{ }^{7} \mathrm{~F}_{1}>{ }^{7} \mathrm{~F}_{4}$, in the entire temperature range.

\section{LM $\mathbf{M}^{4}-1-\mathrm{Nd}$}

The photoluminescence spectrum in the UV-VIS and NIR regions for the $\mathbf{L M}^{\mathbf{4}} \mathbf{- 1 - N d}$ complex is displayed in Fig. 2. The emission spectra present a large and intense band with a maximum at $408 \mathrm{~nm}$, when excited at wavelengths of $330 \mathrm{~nm}$ or $350 \mathrm{~nm}$, which can be attributed to the emission of the 1,10-phenanthroline and LPOM ligands, whereas no emission of the $\mathrm{Nd}^{\mathrm{III}}$ ions in this region is observed (Fig. 2g). The NIR spectrum for $\mathbf{L M}^{\mathbf{4}}$-1-Nd under an excitation at $804 \mathrm{~nm}$ (200 $\mathrm{mW}$ power from a diode laser), associated with ${ }^{4} \mathrm{~F}_{3 / 2} \rightarrow$ ${ }^{4} \mathrm{I}_{11 / 2}$, shows emissions at 890, 1066 and $1343 \mathrm{~nm}$, attributed to the ${ }^{4} \mathrm{~F}_{3 / 2} \rightarrow{ }^{4} \mathrm{I}_{9 / 2},{ }^{4} \mathrm{~F}_{3 / 2} \rightarrow{ }^{4} \mathrm{I}_{11 / 2}$ and ${ }^{4} \mathrm{~F}_{3 / 2} \rightarrow{ }^{4} \mathrm{I}_{13 / 2}$ transitions (Fig. 2h), respectively. ${ }^{56}$ Similar results have been observed for other Nd-POM systems. ${ }^{42}$

Fig. $2 \mathrm{~h}$ shows the NIR emission spectra for $\mathbf{L M}^{\mathbf{4}} \mathbf{- 1}-\mathbf{N d}$ as a function of temperature $(20$ to $300 \mathrm{~K}$ ) under excitation at $804 \mathrm{~nm}$. All the spectral data are normalized with respect to the ${ }^{4} \mathrm{~F}_{3 / 2} \rightarrow{ }^{4} \mathrm{I}_{11 / 2}$ transition intensity taken at $20 \mathrm{~K}$. The intensity of the transition ${ }^{4} \mathrm{~F}_{3 / 2} \rightarrow{ }^{4} \mathrm{I}_{11 / 2}$ is nearly temperature independent, in contrast to the intensity of the ${ }^{4} \mathrm{~F}_{3 / 2} \rightarrow{ }^{4} \mathrm{I}_{13 / 2}$ transition that presents a great temperature dependency. No change in the position of the barycentre of these transitions is observed in the whole temperature range.

\section{$L^{4}$-1-Er and $L M^{4}$-1-Ho complexes}

The $\mathbf{L M}^{\mathbf{4}}$-1-Er emission spectrum (Fig. S13a†) presents two weak emission bands at 546 and $614 \mathrm{~nm}$ attributed to the $\mathrm{Er}^{\mathrm{III}}$ ${ }^{4} \mathrm{~S}_{3 / 2} \rightarrow{ }^{4} \mathrm{I}_{15 / 2}$ and ${ }^{4} \mathrm{~S}_{3 / 2} \rightarrow{ }^{4} \mathrm{I}_{15 / 2}$ transitions, respectively, but does not exhibit emission in the IR region (800-1600 nm) under any excitation or temperature. The emission spectrum of $\mathbf{L M}^{\mathbf{4}} \mathbf{- 1 - H o}$ is depicted in Fig. S13b, $\dagger$ in the range of 450-850 nm, exciting directly the $\mathrm{Ho}^{\text {III }}{ }^{3} \mathrm{~K}_{8}\left(\mathrm{I}_{1}{ }^{\prime}\right)$ energy level, ${ }^{44}$ observing three intense broad bands centred at 510, 552 and $569 \mathrm{~nm}$, and two other small bands at 649 and $660 \mathrm{~nm}$. The high energy bands are attributed to the emission from the two types of ligands and the bands at lower energy are assigned to the ${ }^{5} \mathrm{~F}_{5} \rightarrow{ }^{5} \mathrm{I}_{8}$ transition. As observed for $\mathbf{L} \mathbf{M}^{\mathbf{4}} \mathbf{- 1}$-Er no emission in the infrared region was also observed for $\mathbf{L M}^{\mathbf{4}} \mathbf{- 1}-\mathbf{H o}$.

\section{Energy transfer between ligands and $\mathrm{Ln}^{\mathrm{III}}$ ions}

Latva et $a l .{ }^{60}$ have proposed an empirical rule that establishes the optimal conditions for an efficient energy transfer from a ligand to a metal centre based on the energy difference $\Delta E$ between the triplet excited state $\left(\mathrm{T}_{1}\right)$ and the excited state of $\mathrm{Ln}^{\mathrm{III}}$ ions. This approach has been used by other authors, by 
defining regions depending on the $\mathrm{Ln}^{\mathrm{III}}$ ions, for $\mathrm{Eu}^{\mathrm{III}}$ from 2000 to $5000 \mathrm{~cm}^{-1}$, for Dy ${ }^{\text {III }}$ from 2500 to $4500 \mathrm{~cm}^{-1}$ and for $\mathrm{Tb}^{\mathrm{III}}$ 2000-5000 $\mathrm{cm}^{-1} \cdot{ }^{61-63}$ The emission spectrum of $\mathbf{L M}^{\mathbf{4}} \mathbf{- 1}$ Gd was used to distinguish the emission bands of the ligands (both the organic and inorganic ones) (Fig. S8†). It consists of a broad and intense band centred at $435 \mathrm{~nm}\left(22988 \mathrm{~cm}^{-1}\right)$. Since the energy absorbed by the ligands could not be transfered to the ${ }^{6} \mathrm{P}_{7 / 2}$ energy level at $\sim 312.5 \mathrm{~nm}\left(32000 \mathrm{~cm}^{-1}\right)$ of the $\mathrm{Gd}^{\mathrm{III}}$ ions, the triplet state of the ligand is determined by the lower emission band observed in the $\mathrm{Gd}^{\mathrm{III}}$ spectrum. ${ }^{25}$

For these calculations it has been assumed that the energy transfer process occurs mainly through the phen ligand since it has the most intense emission band compared to the inorganic ligand. The energy transfer level schemes for $\mathbf{L M}^{\mathbf{4}} \mathbf{- 1}$ Dy, $\mathbf{L} \mathbf{M}^{\mathbf{4}} \mathbf{- 1 - T b}, \mathbf{L} \mathbf{M}^{\mathbf{4}} \mathbf{- 1}-\mathbf{E u}$ and $\mathbf{L} \mathbf{M}^{\mathbf{4}} \mathbf{- 1}-\mathbf{N d}$ are shown in Fig. 4 . The triplet energy level of the ligand is higher than that of the lowest $\mathrm{Eu}^{\mathrm{III}}$ excited state at $579 \mathrm{~nm}\left(17267 \mathrm{~cm}^{-1}\right), \Delta E\left[\mathrm{~T}_{1}-{ }^{5} \mathrm{D}_{0}\right]=$ $5721 \mathrm{~cm}^{-1}$, the ${ }^{4} \mathrm{~F}_{9 / 2}$ state of Dy ${ }^{\mathrm{III}}$ at $479 \mathrm{~nm}\left(20877 \mathrm{~cm}^{-1}\right), \Delta E$ $\left[\mathrm{T}_{1}-{ }^{4} \mathrm{~F}_{9 / 2}\right]=2111 \mathrm{~cm}^{-1}$, and to the ${ }^{5} \mathrm{D}_{4} \mathrm{~Tb}^{\mathrm{III}}$ energy level at $486 \mathrm{~nm}\left(20576 \mathrm{~cm}^{-1}\right), \Delta E\left[\mathrm{~T}_{1}-{ }^{5} \mathrm{D}_{4}\right]=2412 \mathrm{~cm}^{-1}$. These results indicate that the emission mechanisms of $\mathrm{Eu}^{\mathrm{III}}$, $\mathrm{Dy}{ }^{\mathrm{III}}$ and $\mathrm{Tb}^{\mathrm{III}}$ compounds correspond to a ligand sensitized photoluminescence process, the so called antenna-effect being in agreement with the difference between the intensity of the ligand and the $\mathrm{Ln}^{\mathrm{III}}$ bands observed in the excitation spectra of $\mathbf{L} \mathbf{M}^{\mathbf{4}}$-1-Dy, $\mathbf{L} \mathbf{M}^{\mathbf{4}} \mathbf{- 1}-\mathbf{T b}$ and $\mathbf{L} \mathbf{M}^{\mathbf{4}}$-1-Eu depicted in Fig. 2a-c-e. ${ }^{5}$ The large experimental $\Delta E$ values indicate that, for $\mathbf{L M}^{\mathbf{4}} \mathbf{- 1}-\mathbf{D y}$, $\mathbf{L M} \mathbf{M}^{\mathbf{4}} \mathbf{- 1}-\mathbf{T b}$ and $\mathbf{L} \mathbf{M}^{\mathbf{4}} \mathbf{- 1 - E u}$, the phen ligand can sensitize more

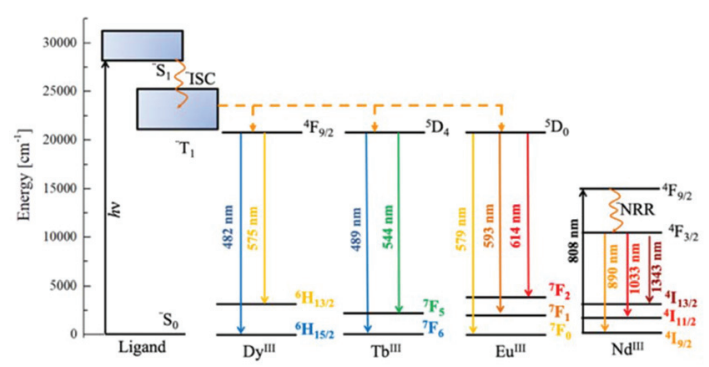

Fig. 4 The energy level diagram and energy transfer schemes for $L M^{4}$ 1-Dy, LM ${ }^{4}-1-T b, L M^{4}-1-E u$ and $L M^{4}-1-N d$. ISC and NRR refer to the intersystem crossing and non-radiative relaxation, respectively. adequately the lanthanoid ions avoiding any energy back transfer in the process. ${ }^{64}$

It is also possible to elucidate the partial energy level scheme for $\mathrm{Nd}^{\mathrm{III}}$ explaining the emission and excitation of $\mathbf{L M}^{\mathbf{4}} \mathbf{- 1 - N d}$ (Fig. 4). It can be inferred that the emission mechanism is a direct excitation of the ${ }^{4} \mathrm{~F}_{9 / 2}$ energy level followed by a non-radiative decay to the ${ }^{4} \mathrm{~F}_{3 / 2}$ level which leads to the three emissions observed, ${ }^{4} \mathrm{~F}_{3 / 2} \rightarrow{ }^{4} \mathrm{I}_{13 / 2},{ }^{4} \mathrm{I}_{13 / 2}$ and ${ }^{4} \mathrm{I}_{13 / 2}$. No $\mathrm{Nd}^{\mathrm{III}}$ emission was observed by exciting the ligand.

The relatively low intensity of the emissions observed (or the absence of these emissions) for $\mathbf{L M}^{\mathbf{4}} \mathbf{- 1}-\mathbf{D y}, \mathbf{L} \mathbf{M}^{\mathbf{4}} \mathbf{- 1}-\mathbf{T b}$ and $\mathbf{L} \mathbf{M}^{\mathbf{4}} \mathbf{- 1 - E u}$, or no emission in the case of $\mathbf{M}^{\mathbf{4}} \mathbf{- 1 - N d}$, in the visible region taken at any temperature, is in accordance with the experimental data reported by Ritchie et al. ${ }^{65}$ for dinuclear and octanuclear $\mathrm{Tb}^{\mathrm{III}}$ and $\mathrm{Eu}^{\mathrm{III}}$ ternary lanthanoidorganic-polyoxometalate (Ln-org-POM) complexes, based on $\left[\mathrm{As}_{2} \mathrm{~W}_{19} \mathrm{O}_{67}\left(\mathrm{H}_{2} \mathrm{O}\right)\right]^{14-}$ and 2-picolinic acid (picH). This is attributed to different relaxation mechanisms such as non-radiative deactivation, and charge-transfer between the excited states of the ligands and the emitting Ln energy levels. Even the nature of the LPOM and the organic ligands play an important role in the photophysical properties of these materials and their applications as temperature sensing systems.

\section{Luminescence lifetimes and colour coordinates}

The luminescence lifetimes of the excited state of $\mathrm{Eu}^{\mathrm{III}}\left({ }^{5} \mathrm{D}_{0}\right)$, $\mathrm{Dy}^{\mathrm{III}}\left({ }^{4} \mathrm{~F}_{9 / 2}\right)$ and $\mathrm{Tb}^{\mathrm{III}}\left({ }^{5} \mathrm{D}_{4}\right)$ ions were estimated from the decay curves shown in Fig. 5. It was obtained by monitoring the emissions at 614,571 , and $543 \mathrm{~nm}$ corresponding to the ${ }^{5} \mathrm{D}_{0} \rightarrow$ ${ }^{7} \mathrm{~F}_{2},{ }^{4} \mathrm{~F}_{9 / 2} \rightarrow{ }^{6} \mathrm{H}_{13 / 2}$ and ${ }^{5} \mathrm{D}_{4} \rightarrow{ }^{7} \mathrm{~F}_{5}$ transitions from Eu ${ }^{\mathrm{III}}$, Dy ${ }^{\mathrm{III}}$ and $\mathrm{Tb}^{\mathrm{III}}$ ions, respectively. The decay curves were fitted with one- and two-exponential functions, obtaining the best results by using the bi-exponential expression $I(t)=A_{1} \exp \left(-t / \tau_{1}\right)+$ $A_{2} \exp \left(-t / \tau_{2}\right)+I_{0}$, where $A_{i}$ represent the integrated areas, $\tau_{1}$ and $\tau_{2}$ are the decay components fast and slow, respectively, and $I_{0}$ is the intensity at $t=0$. The average lifetime $\tau_{\mathrm{AV}}$ can be calculated by using the formula $\tau_{\mathrm{AV}}=\left(A_{1} \tau_{1}^{2}+A_{2} \tau_{2}^{2}\right) /\left(A_{1} \tau_{1}+\right.$ $\left.A_{2} \tau_{2}\right){ }^{66}$ The results of $\tau_{\mathrm{AV}}, \tau_{\mathrm{i}}$ and $A_{\mathrm{i}}$ are given in Table 2 for $\mathbf{L} \mathbf{M}^{\mathbf{4}}$-1-Dy, $\mathbf{L} \mathbf{M}^{\mathbf{4}} \mathbf{- 1}$-Tb and $\mathbf{L} \mathbf{M}^{\mathbf{4}} \mathbf{- 1}-\mathbf{E u}$. The non mono-exponential decay results indicate that two types of transitions are involved in the observed emissions, as pointed by Priya et al. ${ }^{67}$ The short and long lifetimes correspond to two different mecha-
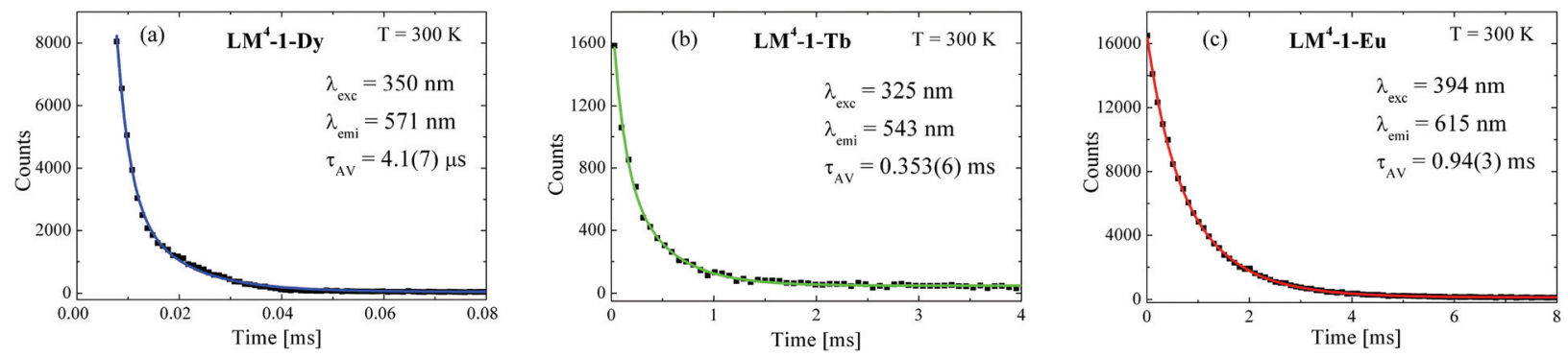

Fig. 5 Luminescence decay curves for $L M^{4}-1-D y(a), L M^{4}-1-T b$ (b) and $L M^{4}-1-E u(c)$ complexes. Symbols and solid lines represent the experimental and theoretical data respectively. 
Table 2 Photometric parameters: experimental lifetimes $\tau$ of the fitted decay curves, CIE $(x, y)$ coordinates, CCT (K) and colour purity (CP) values for Eu', Tb"' and Dy ${ }^{\prime \prime \prime}$ complexes

\begin{tabular}{|c|c|c|c|c|c|c|c|}
\hline Sample & $T(\mathrm{~K})$ & $\begin{array}{l}\tau_{1}(\mathrm{~ms}) \\
\left(A_{1}\right)\end{array}$ & $\begin{array}{l}\tau_{2}(\mathrm{~ms}) \\
\left(A_{2}\right)\end{array}$ & $\tau_{\mathrm{av}}(\mathrm{ms})$ & CIE & CCT (K) & $\mathrm{CP}(\%)$ \\
\hline \multirow[t]{2}{*}{$L M^{4}-1-E u$} & 300 & $\begin{array}{l}1.05(1) \\
(81.6 \%)\end{array}$ & $\begin{array}{l}0.45(1) \\
(18.4 \%)\end{array}$ & $0.94(3)$ & $(0.631,0.364)$ & 1897 & 84 \\
\hline & 17 & & & & $(0.629,0.368)$ & 1846 & 83 \\
\hline \multirow[t]{2}{*}{$L M^{4}-1-T b$} & 300 & $\begin{array}{l}0.432(8) \\
(75.1 \%)\end{array}$ & $\begin{array}{l}0.123(2) \\
(24.9 \%)\end{array}$ & $0.353(6)$ & $(0.185,0.139)$ & n.d. & 48 \\
\hline & 17 & & & & $(0.201,0.176)$ & n.d. & 42 \\
\hline \multirow[t]{2}{*}{$L M^{4}-1-D y$} & 300 & $\begin{array}{l}0.011(2) \\
(18.8 \%)\end{array}$ & $\begin{array}{l}0.003(1) \\
(81.2 \%)\end{array}$ & $0.0041(7)$ & $(0.218,0.177)$ & n.d. & 52 \\
\hline & 17 & & & & $(0.225,0.191)$ & n.d. & 45 \\
\hline
\end{tabular}

nisms: the energy transfer from the ligands to the $\mathrm{Ln}^{\mathrm{III}}$ ions and to the sensitized emission of $\mathrm{Ln}^{\mathrm{III}}$, respectively. At room temperature the average lifetime $\tau_{\mathrm{AV}}$ of the multiplet ${ }^{4} \mathrm{~F}_{9 / 2},{ }^{5} \mathrm{D}_{0}$, and ${ }^{5} \mathrm{D}_{4}$ for $\mathrm{Dy}^{\mathrm{III}}, \mathrm{Eu}^{\mathrm{III}}$ and $\mathrm{Tb}^{\mathrm{III}}$, respectively, was calculated to be $4.1(7) \mu \mathrm{s}, 0.94(3) \mathrm{ms}$ and $0.35(2) \mathrm{ms}$. These values are in good agreement with other reported Ln-POM systems. ${ }^{28,68,69}$

For example, these values are practically the same as for $\left[\mathrm{Eu}\left(\mathrm{W}_{5} \mathrm{O}_{18}\right)_{2}\right]^{9-}$, with a value of $2.8 \mathrm{~ms}$ at $300 \mathrm{~K}$, and approximately 3 times higher than $\left[\mathrm{Eu}_{3}\left(\mathrm{H}_{2} \mathrm{O}\right)_{3}\left(\mathrm{SbW}_{9} \mathrm{O}_{33}\right)\left(\mathrm{W}_{5} \mathrm{O}_{18}\right)_{3}\right]^{18-}$ compound, with a value of $1.1 \mathrm{~ms}$ in all the temperature range (4.2 to $300 \mathrm{~K}) .^{70}$ Moreover, the obtained values for $\mathbf{L M}^{\mathbf{4}} \mathbf{- 1}-\mathbf{T b}$ and $\mathbf{L M}^{\mathbf{4}} \mathbf{- 1 - E u}$ are greater than those reported by Wang et al. ${ }^{24}$ for Lindqvist type POMs containing the 6-peroxoniobio-4-phosphate building block, $\left[\mathrm{Ln}^{\mathrm{III}}\left(\mathrm{H}_{2} \mathrm{O}\right)_{6}\right]\left[\mathrm{H}_{4}\left(\mathrm{NbO}_{2}\right)_{6} \mathrm{P}_{4} \mathrm{O}_{24}\right] \cdot n \mathrm{H}_{2} \mathrm{O}$ $(\mathrm{Ln}=\mathrm{Dy}, \mathrm{Eu}, \mathrm{Tb})$, where the $\mathrm{Ln}^{\mathrm{III}}$ ions are coordinated with eight oxygens, six of them being from water molecules, $\tau_{\mathrm{Tb}} \approx$ $0.018 \mathrm{~ms}$ and $\tau_{\mathrm{Eu}} \approx 0.148 \mathrm{~ms}$.

The intrinsic quantum efficiency $(\eta)$ for $\mathbf{L} \mathbf{M}^{\mathbf{4}} \mathbf{- 1}-\mathbf{E u}$ was calculated through the ratio of $\tau_{\mathrm{AV}}$ and $\tau_{\text {rad }}$ obtained from the JuddOfelt theory, ${ }^{71}$ and the value is $\sim 34.1 \%$. The internal and external quantum yields (iQy and eQy) of the ${ }^{5} \mathrm{D}_{0} \rightarrow{ }^{7} \mathrm{~F}_{J}$ emission of $\mathbf{L M}^{\mathbf{4}}$-1-Eu under $394 \mathrm{~nm}$ excitation are 4.3 and $1.7 \%$, respectively. These QY values are associated with the energy gap of $\mathrm{Eu}^{\mathrm{III}}{ }^{5} \mathrm{D}_{0} \rightarrow{ }^{7} \mathrm{~F}_{4}\left(712 \mathrm{~nm}, 14045 \mathrm{~cm}^{-1}\right)$ that matches with the overtones of $\mathrm{C}-\mathrm{H}$ and $\mathrm{O}-\mathrm{H}$ vibration frequencies, $3 \nu \approx$ $13953 \mathrm{~cm}^{-1}$, that promote a small emission quantum yield and a temperature-dependent luminescence, as observed for $\mathbf{L M}^{\mathbf{4}} \mathbf{- 1}-\mathbf{E u}$, similar analysis can be made for both $\mathbf{L} \mathbf{M}^{\mathbf{4}}$-1-Dy and $\mathbf{L} \mathbf{M}^{\mathbf{4}}$-1-Tb compounds. The quantum yield values obtained for $\mathbf{L M}^{\mathbf{4}} \mathbf{- 1 - E \mathbf { E }}$ are quite higher compared to those of fully inorganic systems like $\left[\mathrm{Eu}\left(\mathrm{W}_{5} \mathrm{O}_{18}\right)_{2}\right]^{9-}$ and $\left[\mathrm{Eu}_{3}\left(\mathrm{H}_{2} \mathrm{O}\right)_{3}\left(\mathrm{SbW}_{9} \mathrm{O}_{33}\right)\left(\mathrm{W}_{5} \mathrm{O}_{18}\right)_{3}\right]^{18-}$ compounds, with a QY of ca. $1 \% .^{70}$

The CIE 1931 (Commission International d'Eclairage) ${ }^{72}$ diagram is a universal method for studying all the possible colours using the photoluminescence spectra and the changes in the intensity of the emission bands by determining the chromaticity coordinates $(x, y)$. These coordinates are usually employed to distinguish the precision emission colours. For Dy ${ }^{\mathrm{II}}$ and $\mathrm{Tb}^{\mathrm{III}}$ complexes the $(x, y)$ chromaticity coordinates lie in the blueish region, respectively, $(0.215,0.174)$ and

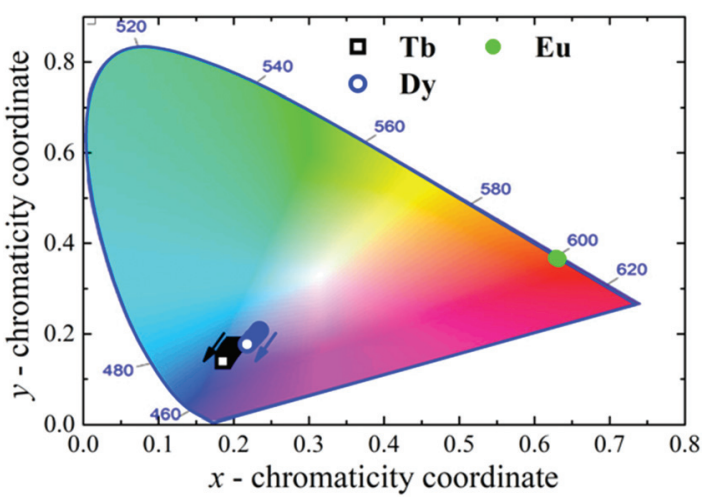

Fig. 6 CIE 1931 chromaticity coordinate diagram in $\mathrm{LM}^{4}-1-\mathrm{Ln}\left(\mathrm{Ln}^{\mathrm{III}}=\right.$ Eu ${ }^{\prime \prime \prime}$, Dy ${ }^{\prime \prime \prime}$ and Tb ${ }^{\prime \prime \prime}$ ) complexes vs. temperature.

$(0.175,0.125)$, while for the Eu ${ }^{\mathrm{III}}$ complex $(0.631,0.364)$ lies in the deep red region of the CIE diagram, near to the coordinates for ideal red phosphors (Fig. 6 and Table 2) ${ }^{73}$ These values can be compared with the $\left\{\left[\mathrm{Ln}_{2}(\mathrm{DMF})_{8}\left(\mathrm{H}_{2} \mathrm{O}\right)_{6}\right]\left[\mathrm{ZnW}_{12} \mathrm{O}_{40}\right]\right\} \cdot 4 \mathrm{DMF}$ complex reported by Zhao et al. ${ }^{74}$ whereas they report that for the $\mathrm{Tb}^{\mathrm{III}}$ analogue, the coordinates lie in the green region in contrast to that reported in this work that lies in the blue region. This could be because the emission spectrum for $\mathbf{L M} \mathbf{M}^{\mathbf{4}}$-1-Dy and $\mathbf{L} \mathbf{M}^{\mathbf{4}} \mathbf{- 1}$-Tb complexes presents an important contribution coming from the organic and inorganic ligand emission, absent in the $\left\{\left[\mathrm{Tb}_{2}(\mathrm{DMF})_{8}\left(\mathrm{H}_{2} \mathrm{O}\right)_{6}\right]\left[\mathrm{ZnW}_{12} \mathrm{O}_{40}\right]\right\} \cdot 4 \mathrm{DMF}$ compound.

The colour purity of complexes $\mathbf{L} \mathbf{M}^{\mathbf{4}} \mathbf{- 1}-\mathbf{D y}, \mathbf{L} \mathbf{M}^{\mathbf{4}} \mathbf{- 1}-\mathbf{T b}$ and $\mathbf{L M}^{\mathbf{4}}$-1-Eu was calculated by using the equation: ${ }^{75}$

$$
\mathrm{CP}=\sqrt{\frac{\left(x-x_{\mathrm{i}}\right)^{2}+\left(y-y_{\mathrm{i}}\right)^{2}}{\left(x_{\mathrm{d}}-x_{\mathrm{i}}\right)^{2}+\left(y_{\mathrm{d}}-y_{\mathrm{i}}\right)^{2}}} \times 100 \%
$$

where CP is the colour purity, $(x, y)$ for each sample given in Table $2,\left(x_{\mathrm{i}}, y_{\mathrm{i}}\right)=(0.333,0.333)$ and $\left(x_{\mathrm{d}}, y_{\mathrm{d}}\right)$ are, respectively, the colour coordinates of the overall light emitted by each $[\mathrm{LnH}$ $\left.\left(\mathrm{PW}_{11} \mathrm{O}_{39}\right)(\text { phen })_{2}\right]^{3-}$ complex, the standard white light and the dominant wavelength point, $(0.688,0.331)$ for red, $(0.15,0.06)$ for blue and $(0.29,0.60)$ for green colour. 
The calculated CP values are $47.6 \%, 52.0 \%$ and $84.6 \%$ for $\mathbf{L M}^{\mathbf{4}}$-1-Dy, $\mathbf{L} \mathbf{M}^{\mathbf{4}} \mathbf{- 1}-\mathbf{T b}$ and $\mathbf{L} \mathbf{M}^{\mathbf{4}} \mathbf{- 1}-\mathbf{E u}$, respectively. The CP value found for $\mathbf{L} \mathbf{M}^{\mathbf{4}} \mathbf{- 1}$-Dy is very close to the one reported by $\mathrm{Wu}$ et $a .^{69}$ for $\left[\mathrm{N}\left(\mathrm{CH}_{3}\right)_{4}\right]_{6} \mathrm{~K}_{3} \mathrm{H}_{7}\left[\mathrm{Dy}\left(\mathrm{C}_{4} \mathrm{H}_{2} \mathrm{O}_{6}\right)\left(\mathrm{PW}_{11} \mathrm{O}_{39}\right)\right]_{2}$, with a $\mathrm{CP}$ value of $c a .43 .35 \%$. The correlated colour temperature (CCT) values were calculated, using the McCamy formula: CCT = $-437 n^{3}+360 n^{2}-6861 n+5514.31$, where $n=\left(x-x_{\mathrm{c}}\right) /\left(y-y_{\mathrm{c}}\right), x$ and $y$ being the chromaticity coordinates, and $x_{\mathrm{c}}=0.3320$ and $y_{\mathrm{c}}=0.1858$ being the coordinates of the chromaticity epicentre extracted from a report by McCamy et al. ${ }^{76}$ The found values for Eu ${ }^{\mathrm{III}}$ range between $1846 \mathrm{~K}$ at $17 \mathrm{~K}$ and $1897 \mathrm{~K}$ at $300 \mathrm{~K}$. For $\mathrm{Dy}^{\mathrm{III}}$ and $\mathrm{Tb}^{\mathrm{III}}$ it was not possible to determine this parameter.

\section{Thermometric studies}

The temperature dependency of the ratio between the $\mathrm{Ln}^{\mathrm{III}}$ emission intensity and the ligand emission intensity, related to the phen and LPOM, for $\mathbf{L} \mathbf{M}^{\mathbf{4}} \mathbf{- 1}$-Dy and $\mathbf{L} \mathbf{M}^{\mathbf{4}} \mathbf{- 1}-\mathbf{T b}$ is analysed from $20 \mathrm{~K}$ to $300 \mathrm{~K}$. For $\mathbf{L M}^{\mathbf{4}}$-1-Dy (Fig. 7a), in the range of 120 to $300 \mathrm{~K}$, the ratio between the intensity of the emission associated with the Dy ${ }^{\mathrm{III}}$ transition ${ }^{4} \mathrm{~F}_{9 / 2} \rightarrow{ }^{6} \mathrm{H}_{13 / 2}$ at $479 \mathrm{~nm}$ and the intensity of the ligand emission $\left(I_{6} \mathrm{H}_{13 / 2} / I_{\text {ligand }}\right)$ shows a decrease in this temperature range, and between the 20 to $120 \mathrm{~K}$ range, the intensity ratio value becomes almost constant. For the temperature dependency of the ratio between the intensity of the ${ }^{4} \mathrm{~F}_{9 / 2} \rightarrow{ }^{6} \mathrm{H}_{15 / 2}$ transition (at $571 \mathrm{~nm}$ ) and the intensity of the ligand emission $\left({ }^{6} \mathrm{H}_{15 / 2} / I_{\text {ligand }}\right)$ a similar trend is observed. The linear parts follow these equations: $I^{{ }^{6} \mathrm{H}_{15 / 2}} / I_{\text {ligand }}=1.71-0.0028 T$ and $I_{6} \mathrm{H}_{13 / 2} / I_{\text {ligand }}=1.51-0.0026 T$. Thus, the ratios of both Dy ${ }^{\text {III }}$ transitions decrease with, approximately, the same relative sensitivity $c a . \sim 0.27 \%$ per Kelvin.

For the $\mathbf{L} \mathbf{M}^{\mathbf{4}} \mathbf{- 1}-\mathbf{T b}$ complex, the ratios were calculated between the intensities of the $\mathrm{Tb}^{\mathrm{III}}{ }^{5} \mathrm{D}_{4} \rightarrow{ }^{7} \mathrm{~F}_{5,6}$ transitions (at 486 and $542 \mathrm{~nm}$, respectively) and the intensity of the ligand emission $\left(I_{7} \mathrm{~F}_{5,6} / I_{\text {ligand }}\right)$, Fig. $7 \mathrm{~b}$. The results show a linear decrease over the entire temperature range, which follows these equations: $I_{7} \mathrm{~F}_{6} / I_{\text {ligand }}=0.41-0.0003 T$ and ${ }^{I_{7}} \mathrm{~F}_{5} / I_{\text {ligand }}=0.61-0.0007 T$, indicating that for $\mathbf{L M}^{\mathbf{4}} \mathbf{- 1 - \mathbf { T b }}$ the relative sensitivities are 0.03 and $0.07 \%$ per $\mathrm{K}$. These results are in contrast to the obtained intensity ratios for $\mathbf{L M}^{\mathbf{4}} \mathbf{- 1}-\mathbf{D y}$, where the rates for the two transitions are similar. One possible explanation for this difference is the relative sensitivity of $\mathbf{L M} \mathbf{M}^{\mathbf{4}} \mathbf{- 1}$-Dy compared to the $\mathbf{L} \mathbf{M}^{\mathbf{4}} \mathbf{- 1}$ - $\mathbf{T b}$ sensitivity, since for $\mathbf{L} \mathbf{M}^{\mathbf{4}}$ 1-Tb the emission band of both ligands is more intense, broad and closer to the first $\mathrm{Tb}^{\mathrm{III}}$ emission line. In the case of $\mathbf{L M}^{\mathbf{4}} \mathbf{- 1}$ Dy, for the same emission bands of the ligands the intensity is less intense than the nearest Dy ${ }^{\mathrm{III}}$ emission (see Fig. $2 \mathrm{~b}, \mathrm{~d}, 7 \mathrm{a}$ and b). The lower emission intensities for $\mathrm{Dy}^{\mathrm{III}}$ and $\mathrm{Tb}^{\mathrm{III}}$ emission with the increase of temperature are principally due to thermal nonradiative deactivation pathways involving the $\mathrm{Ln}^{\mathrm{III}}$ energy levels and the excited state from the two types of ligands of the complexes.

For the $\mathbf{L M}^{\mathbf{4}}$-1-Dy compound the $I_{\text {Dy }}$ iII $/ I_{\text {ligand }}$ ratios indicate that the intensity of the ${ }^{4} \mathrm{~F}_{9 / 2} \rightarrow{ }^{6} \mathrm{H}_{13 / 2}$ and ${ }^{4} \mathrm{~F}_{9 / 2} \rightarrow{ }^{6} \mathrm{H}_{15 / 2}$ transitions decreases by $\sim 35 \%$ from 140 to 300 K. For $\mathbf{L M}^{\mathbf{4}} \mathbf{- 1}-\mathbf{T b}$, the $I_{\mathrm{Tb}}$ iII $/ I_{\text {ligand }}$ ratios, from 20 to $300 \mathrm{~K}$, indicate that the tran-
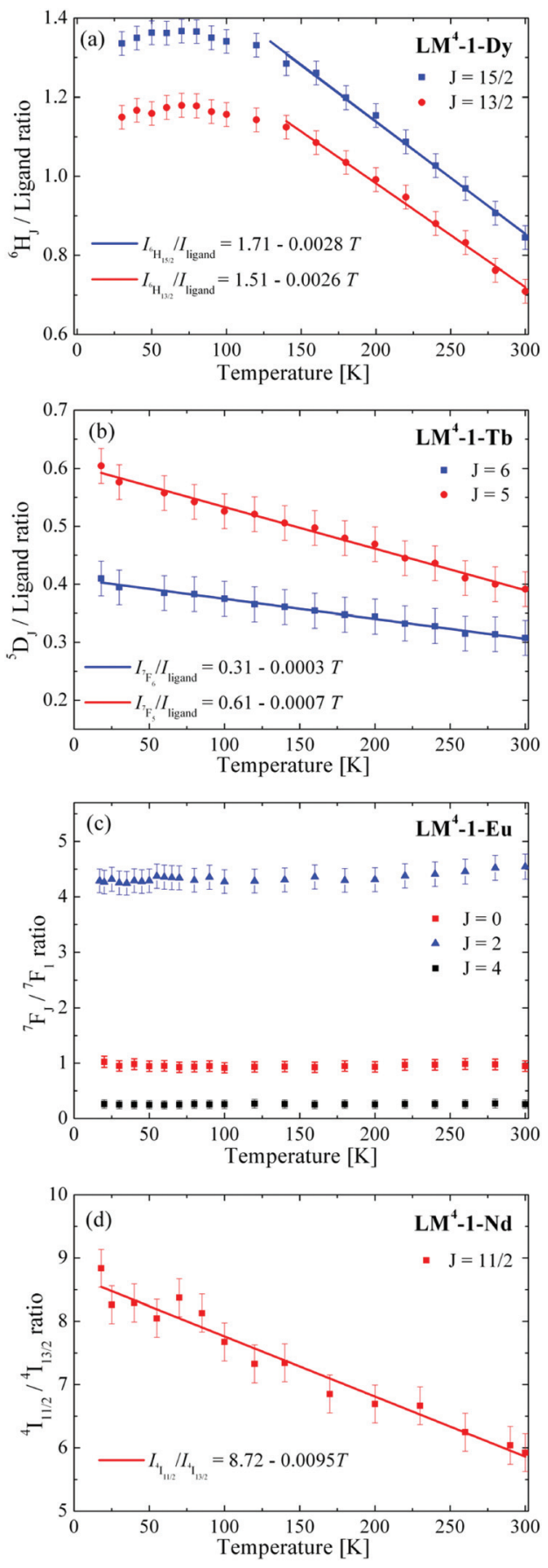

Fig. 7 Temperature dependent intensity ratios of (a) Dy ${ }^{\prime \prime I}{ }^{4} \mathrm{~F}_{9 / 2} \rightarrow$ ${ }^{6} \mathrm{H}_{15 / 2,13 / 2}$ transitions to ligands (b) $\mathrm{Tb}^{111}{ }^{5} \mathrm{D}_{4} \rightarrow{ }^{7} \mathrm{~F}_{5,6}$ transitions to ligands, (c) ${ }^{7} \mathrm{~F}_{0,2,4}$ by ${ }^{7} \mathrm{~F}_{1}$ from Eu$u^{11 \prime \prime}{ }^{5} \mathrm{D}_{0} \rightarrow{ }^{7} \mathrm{~F}_{0,1,2,4}$ transitions and (d) $\mathrm{Nd}^{\text {III: }}$ ${ }^{4} I_{11 / 2} / I^{4} I_{13 / 2}$ emissions. Solid lines in (a), (b) and (d) are the best linear fits.

sitions at 486 and $572 \mathrm{~nm}$ decrease by 32 and 10\%, respectively. These results indicate an important role in the temperature response for both monitored Dy ${ }^{\mathrm{III}}$ transitions $\left({ }^{4} \mathrm{~F}_{9 / 2} \rightarrow\right.$ ${ }^{6} \mathrm{H}_{15 / 2,13 / 2}$ ) and for the ${ }^{5} \mathrm{D}_{4} \rightarrow{ }^{7} \mathrm{~F}_{5}$ transition at $486 \mathrm{~nm}$ of $\mathrm{Tb}^{\mathrm{III}}$, in accordance with the CIE chromaticity diagram (Fig. 6), where it can be observed that $\mathbf{L} \mathbf{M}^{\mathbf{4}} \mathbf{- 1}-\mathbf{D y}$ and $\mathbf{L} \mathbf{M}^{\mathbf{4}} \mathbf{- 1}-\mathbf{T b}$ show small CIE coordinates temperature dependence. 
For $\mathbf{L M}^{\mathbf{4}} \mathbf{- 1}-\mathbf{N d}$, the $\mathrm{Nd}^{\mathrm{III}}$ transitions $\left({ }^{4} \mathrm{~F}_{3 / 2} \rightarrow{ }^{4} \mathrm{I}_{11 / 2,13 / 2}\right)$ do not present overlap and were used to evaluate the temperature response of $\mathrm{Nd}^{\mathrm{III}}$ emission. The ratio $I_{4} \mathrm{I}_{11 / 2} / I_{4} \mathrm{I}_{13 / 2}$ decreases linearly from 20 to $300 \mathrm{~K}$, and can be fitted with the linear function: ${ }^{I_{4}} \mathrm{I}_{11 / 2} / I^{I_{4}} \mathrm{I}_{13 / 2}=8.72-0.0095 T$, i.e., the relative sensitivity of the ${ }^{I_{4}} \mathrm{I}_{11 / 2}$ intensity from 20 to $300 \mathrm{~K}$ is $0.95 \%$, being the highest among the studied complexes (Fig. 7d).

The obtained relative sensitivities of $\mathbf{L M}^{\mathbf{4}} \mathbf{- 1}-\mathbf{D y}, \mathbf{L} \mathbf{M}^{\mathbf{4}} \mathbf{- 1}-\mathbf{T b}$, and $\mathbf{L M}^{\mathbf{4}}$-1-Nd can be compared with those of the $\left[\mathrm{EuW}_{10} \mathrm{O}_{36}\right]^{9-}$ polyoxometalate reported by Salomon et al. ${ }^{77}$ with a relative sensitivity of $0.26 \% \mathrm{~K}^{-1}$. As reported by $\mathrm{Xu}$ et al. ${ }^{78}$ the thermometric mechanisms could be explained by the fact that as the temperature increases, the number of molecules in the excited state energy level will gradually increase in proportion, while the ratio of the number of molecules in the excited state of the low energy level will reduce. Thus, the intensity ratios of the $\mathrm{Ln}^{\mathrm{III}}$ bands with the ligand band undergo a remarkable decrease as the temperature increases.

Finally, the $\mathbf{L} \mathbf{M}^{\mathbf{4}} \mathbf{- 1}-\mathbf{D y}, \mathbf{L} \mathbf{M}^{\mathbf{4}} \mathbf{- 1}-\mathbf{T b}$, and $\mathbf{L} \mathbf{M}^{\mathbf{4}} \mathbf{- 1}-\mathbf{N d}$ compounds have the necessary requirement to have potential applications as temperature sensors. Furthermore, $\mathbf{L} \mathbf{M}^{\mathbf{4}} \mathbf{- 1 - D y}$ and $\mathbf{L} \mathbf{M}^{\mathbf{4}} \mathbf{- 1}-\mathbf{T b}$ have an energy gap between the emitting $\mathrm{Ln}^{\mathrm{III}}$ levels and the excite sates of the ligands, in the range of 200 to $2000 \mathrm{~cm}^{-1}$, avoiding any overlap between them. ${ }^{2}$

\section{Experimental}

\section{Materials and reagents}

FTIR-ATR (Fourier Transform Infrared-Attenuated Total Reflectance) spectra (4000-400 $\left.\mathrm{cm}^{-1}\right)$ of the compounds were obtained using a Jasco FTIR-4600 spectrophotometer equipped with an ATR PRO ONE (Jasco, Easton, MD, USA), Fig. S1.† Elemental analyses (C, N, H) of bulk samples were performed using a Thermo elemental analyser Flash 2000. The Ln : P : W ratios of the bulk samples were estimated by electron probe microanalysis (EPMA) performed with a Jeol, JSM 5410 equipped with an EDAX NORAN microprobe, Table S1. $\dagger$ Amorphous, polycrystalline or crystalline samples of all compounds were lightly ground with a pestle in an agate mortar and filled into $0.5 \mathrm{~mm}$ borosilicate capillaries prior to being mounted and aligned on an Empyrean PANalytical powder diffractometer, using $\mathrm{Cu} \mathrm{K \alpha}$ radiation $(\lambda=1.54056 \AA)$. For each sample, two or three repeated measurements were collected at room temperature $\left(2 \theta=2-40^{\circ}\right)$ and merged into a single diffractogram.

\section{Synthesis of $\left[n-\mathrm{NBu}_{4}\right]_{3}\left[\mathrm{LnH}\left(\mathrm{PW}_{11} \mathrm{O}_{39}\right)(\text { phen })_{2}\right] \cdot\left[\mathrm{H}_{2} \mathrm{O}\right]$}

All chemical reagents were directly used without further purification. $\left[\mathrm{n}-\mathrm{NBu}_{4}\right]_{4}\left[\mathrm{PW}_{11} \mathrm{O}_{39} \mathrm{H}_{3}\right]$ was synthesized according to a previously reported method. ${ }^{79}$ Hydrothermal synthesis was done using a Parr reactor of $23 \mathrm{ml}$ model 4749.

The corresponding hydrated $\mathrm{Ln}^{\mathrm{III}}$ acetates $(0.1 \mathrm{mmol})$, $\mathrm{LnAc}_{3} \cdot \mathrm{XH}_{2} \mathrm{O}$ where $\mathrm{Ln}^{\mathrm{III}}=\mathrm{Dy}^{\mathrm{III}}\left(\mathbf{L M}^{\mathbf{4}} \mathbf{- 1}-\mathbf{D y}\right), \mathrm{Tb}^{\mathrm{III}}\left(\mathbf{L M}^{\mathbf{4}} \mathbf{- 1}-\mathbf{T b}\right)$, $\mathrm{Eu}^{\mathrm{III}}\left(\mathbf{L M}^{\mathbf{4}}\right.$-1-Eu$), \mathrm{Nd}^{\mathrm{III}}\left(\mathbf{L M}^{\mathbf{4}} \mathbf{- 1}-\mathbf{N d}\right), \operatorname{Er}^{\mathrm{III}}\left(\mathbf{L M}^{\mathbf{4}} \mathbf{- 1}-\mathbf{E r}\right), \mathrm{Ho}^{\mathrm{III}}\left(\mathbf{L M}^{\mathbf{4}} \mathbf{- 1}-\right.$ Ho) and $\mathrm{Gd}^{\mathrm{III}}\left(\mathbf{L M}^{\mathbf{4}} \mathbf{- 1}-\mathbf{G d}\right)$ were mixed with $\left[\mathrm{NBu}_{4}\right]_{4}\left[\mathrm{PW}_{11} \mathrm{O}_{39} \mathrm{H}_{3}\right]$
(365 mg, $0.1 \mathrm{mmol}$ ) and phenanthroline (0.036 mg, $0.2 \mathrm{mmol}$ ) in $10 \mathrm{~mL}$ of water in a Parr reactor and heated under autogenous pressure at $160{ }^{\circ} \mathrm{C}$ for 48 hours. The reaction mixture was filtered off, and pale pink crystals of $\mathbf{L M}^{\mathbf{4}} \mathbf{- 1}-\mathbf{L n}$, suitable for $\mathrm{X}$-ray diffraction, were obtained by mechanical separation. Then, these crystals were washed with water and acetone. For more information see section S1 and S2 in the ESI. $\dagger$

\section{Physical measurements}

The single crystals obtained were mounted on the tip of a glass fibre. The intensities for $\mathbf{L M}^{\mathbf{4}} \mathbf{- 1}-\mathbf{L n}$ were recorded on a Bruker Smart Apex diffractometer, using separations of $0.3^{\circ}$ between frames and $10 \mathrm{~s}$ by frame. Datasets were reduced by using SAINTPLUS, ${ }^{80}$ while the structure was solved by direct methods and completed by Difference Fourier Synthesis. Least-squares refinement was conducted by using SHELXL. ${ }^{81,82}$ All atoms were anisotropically refined. However, the $\mathrm{N}$ and $\mathrm{C}$ atoms of the tetra- $n$-butylammonium cations were isotropically refined. Hydrogen atom positions were calculated after each cycle of refinement with SHELXL using a riding model for each structure, with a $\mathrm{C}-\mathrm{H}$ distance of $0.93 \AA$ or $0.97 \AA$. $U_{\text {iso }}(H)$ values were set equal to $1.2 U_{\text {eq }}$ of the parent carbon atom. Additional crystallographic and refinement details are given in Table $\mathrm{X} . \dagger$ Structural drawings were carried out with DIAMOND-3.2k, supplied by Crystal Impact. ${ }^{83}$ Crystallographic data for the structure reported in this paper have been deposited with the Cambridge Crystallographic Data Centre as supplementary publication number CCDC 1951517 for 1-Tb, 1962564 for 1-Eu, 1962563 for 1-Nd and 1951518 for $\mathbf{1 - H o} \dagger$ The crystallographic data of $\mathbf{L M}^{\mathbf{4}} \mathbf{- 1}-\mathbf{D} \mathbf{D}$, $\mathbf{L M}^{\mathbf{4}}$-1-Er and $\mathbf{L} \mathbf{M}^{\mathbf{4}}$-1-Gd have been reported previously. ${ }^{27}$

\section{Optical measurements}

Solid-state absorption spectra were obtained on a PerkinElmer Lambda 1050 spectrometer, operating in the 350 to $2500 \mathrm{~nm}$ spectral range, making a $\mathrm{KBr}$ pellet with $\mathbf{L M}^{\mathbf{4}}$-1-Ln complexes. Photoluminescence (PL) emission spectra of the solid samples were obtained using a Horiba-Jobin Yvon spectrofluorimeter, Model Fluorolog-3 (FL3-221), under excitation with a $450 \mathrm{~W}$ Xe lamp and Horiba PPD-850 picosecond photon detector in the UV-VIS region and an InGaAs detector in the infrared region. The excitation and emission slits used were of $1.15 \mathrm{~nm}$. PL emission was corrected for the spectral response of the monochromators and the detector using a typical correction spectrum provided by the manufacturer. The luminescence decay curves were obtained by using a $50 \mathrm{~W}$ Xe-pulse lamp. Lowtemperature spectra were obtained, using a closed cycle cryostat model CS202AI-X15 (ARS Cryo) monitoring the temperature with a Lake Shore model 332 controller. The quantum yield (QY) of the $\mathrm{Ln}^{\mathrm{III}}$ emission of all complexes was acquired using an integrating sphere (Quanta- $\varphi$ equipment, F3029, Horiba Jobin Yvon) of Spectralon ${ }^{\circledR}$ coupled by means of optical fibers. The internal and external QYs were calculated following the method developed by Wrighton et al. ${ }^{84}$ The internal and external photoluminescence quantum yields $(\Phi)$ were determined with the FluorEssence V3.5 software that 
compares the number of photons emitted by the sample with the number of reflected photons from the reflection standard (Spectralon $\left.{ }^{\circledR}\right) .{ }^{85}$ For IR emission measurements a diode laser (Crystal Laser LC) with a power of $200 \mathrm{~mW}$ was used.

\section{Conclusions}

In summary, this article describes the synthesis, crystal structure and photophysical properties of a family of mononuclear hybrid organic-inorganic lanthanoid complexes $\left(\mathrm{Ln}=\mathrm{Dy}^{\mathrm{III}}\right.$, $\mathrm{Tb}^{\mathrm{III}}, \mathrm{Eu}^{\mathrm{III}}, \mathrm{Nd}^{\mathrm{III}}, \mathrm{Er}^{\mathrm{III}}, \mathrm{Ho}^{\mathrm{III}}$ and $\left.\mathrm{Gd}^{\mathrm{III}}\right)$. All $\mathrm{Ln}^{\mathrm{III}}$ ions are eightcoordinated with $4 \mathrm{O}$ atoms from the lacunary Keggin POM $\left[\mathrm{PW}_{11} \mathrm{O}_{39}\right]^{7-}$ and $4 \mathrm{~N}$ atoms from the phen molecules, with a square-antiprism geometry (pseudo $D_{4 \mathrm{~d}}$ symmetry). As the minor distance between $\operatorname{Ln}^{\text {III }}$ ions is $\sim 10 \AA$ the energy transfer process by the exchange mechanism is almost absent, so the principal mechanism occurs through the ligands and the emitting levels of $\mathrm{Ln}^{\mathrm{III}}$ ions. The thermal-dependence of the luminescence intensity ratios $\mathbf{Y} / \mathbf{B}, \mathbf{R} / \mathbf{O}$ and $\mathbf{G} / \mathbf{B}$ of $\mathbf{L M}^{\mathbf{4}} \mathbf{- 1}-\mathbf{E u}$, $\mathbf{L} \mathbf{M}^{\mathbf{4}}$-1-Eu and $\mathbf{L} \mathbf{M}^{\mathbf{4}} \mathbf{- 1}-\mathbf{T b}$, respectively, indicates that these compounds present a thermal structural stability and lanthanoid emissions within the studied temperature range. On the other hand, the ratios between lanthanoid and ligand emissions change as a function of temperature giving the possibility of being used as thermosensors with good sensitivity (from $140 \mathrm{~K}$ to $300 \mathrm{~K}$ for the $\mathbf{L M}^{\mathbf{4}}$-1-Dy complex, and from $20 \mathrm{~K}$ to $300 \mathrm{~K}$ for the $\mathbf{L} \mathbf{M}^{\mathbf{4}} \mathbf{- 1}-\mathbf{T b}$ and $\mathbf{L} \mathbf{M}^{\mathbf{4}} \mathbf{- 1 - N d}$ complexes). The CIE coordinates and the high colour purity values for $\mathbf{L M}^{\mathbf{4}} \mathbf{- 1 - T b}$ and $\mathbf{L} \mathbf{M}^{\mathbf{4}} \mathbf{- 1 - E u}$ show that these compounds are good candidates to be applied as red and blue components of WLEDs. Also, for the $\mathbf{L M}^{\mathbf{4}} \mathbf{- 1}-\mathbf{E u}$ complex the Judd-Ofelt intensity parameters were determined from the emission spectra. The obtained value for the $\Omega_{2}$ parameter suggests a moderate covalent degree of the metal-ligand bonds. The temperature luminescence studies of $\mathbf{L M}^{\mathbf{4}} \mathbf{- 1}-\mathbf{E u}$ show that the intensity, CIE coordinates and CCT values do not change in the temperature range of 20 to $300 \mathrm{~K}$, and a quantum yield of $4.3 \%$ is obtained, which is four times larger than that of the fully inorganic analogue, conferring to this material interesting characteristics for applications as active media in red OLEDs or even in the catalytic and biological imaging fields.

\section{Abbreviations}

$\begin{array}{ll}\text { phen } & \text { 1,10-Phenanthroline } \\ \text { POM } & \text { Polyoxometalate } \\ \text { MOF } & \text { Metal organic framework } \\ \text { LPOM } & \text { Lacunary polyoxometalate } \\ \text { DMF } & \text { Dimethylformamide } \\ \text { picH } & \text { 2-Picolinic acid } \\ \text { iQY } & \text { Internal quantum yield } \\ \text { eQY } & \text { External quantum yield } \\ \text { CIE } & \text { Commission International d'Eclairage } \\ \text { CCT } & \text { Correlated colour temperature }\end{array}$

OLED Organic light-emitting diode

WLED White light-emitting diode

dpa Dipicolinate

\section{Conflicts of interest}

There are no conflicts to declare.

\section{Acknowledgements}

W. C.-M. thanks FONDECYT 11160830 for financial support. The authors thank the REDI170277 project for financial support. The authors also acknowledge the partial support from Financiamiento Basal AFB180001 (CEDENNA). This work was done under the LIA-M3-1027 CNRS Collaborative Program. The present work has been also funded by the Spanish MICINN (Unidad de Excelencia "María de Maeztu" MDM-2015-0538 and project CTQ2017-89528-P), and the Generalitat Valenciana (PROMETEU/2019/066). G. M. E acknowledges MICINN for a Ramón y Cajal contract. This study was financed in part by the Coordenação de Aperfeiçoamento de Pessoal de Nível Superior (CAPES) Conselho Nacional de Desenvolvimento Científico e Tecnológico (CNPq), Fundação de Amparo à Pesquisa do Estado de Goiás (FAPEG) and Financiadora de Estudos e Projetos (FINEP) Brazilian agencies.

\section{References}

1 Y. Hasegawa, Y. Kitagawa and T. Nakanishi, Effective Photosensitized, Electrosensitized, and Mechanosensitized Luminescence of Lanthanide Complexes, NPG Asia Mater., 2018, 10, 52-70.

2 Y. Hasegawa and Y. Kitagawa, Thermo-Sensitive Luminescence of Lanthanide Complexes, Clusters, Coordination Polymers and Metal-Organic Frameworks with Organic Photosensitizers, J. Mater. Chem. C, 2019, 7, 7494-7511.

3 J. H. Kim, Y. Jung, D. Lee and W. D. Jang, Thermoresponsive Polymer and Fluorescent Dye Hybrids for Tunable Multicolor Emission, Adv. Mater., 2016, 28, 3499-3503.

4 M. S. Deshmukh, A. Yadav, R. Pant and R. Boomishankar, Thermochromic and Mechanochromic Luminescence Umpolung in Isostructural Metal-Organic Frameworks Based on $\mathrm{Cu}_{6} \mathrm{I}_{6}$ Clusters, Inorg. Chem., 2015, 54, 1337-1345.

$5 \mathrm{~K}$. Binnemans, Lanthanide-Based Luminescent Hybrid Materials, Chem. Rev., 2009, 109, 4283-4374.

6 L. D. Carlos, R. A. S. Ferreira, V. de Z. Bermudez and S. J. L. Ribeiro, Lanthanide-Containing Light-Emitting Organic-Inorganic Hybrids: A Bet on the Future, Adv. Mater., 2009, 21, 509-534.

7 D. F. Parra, A. Mucciolo and H. F. Brito, Green Luminescence System Containing a $\mathrm{Tb}^{3+} \beta$-Diketonate 
Complex Doped in the Epoxy Resin as Sensitizer, J. Appl. Polym. Sci., 2004, 94, 865-870.

8 A. O. Ribeiro and O. A. Serra, Spectroscopic Study of $\left[\mathrm{Tb}^{3+}(\beta \text {-Diketonate })_{3}\right]$ : Alpha-Cyclodextrin Inclusion Compounds in Aqueous Solution, J. Braz. Chem. Soc., 2007, 18, 273-278.

9 M. Elbanowski and B. Mąkowska, The Lanthanides as Luminescent Probes in Investigations of Biochemical Systems, J. Photochem. Photobiol., A, 1996, 99, 85-92.

$10 \mathrm{~J}$. Zhao, L. Huang, T. Liang, S. Zhao and S. Xu, Luminescent Properties of $\mathrm{Eu}^{3+}$ Doped Heavy Tellurite Scintillating Glasses, J. Lumin., 2019, 205, 342-345.

11 C. Boskovic, Rare Earth Polyoxometalates, Acc. Chem. Res., 2017, 50, 2205-2214.

12 X. Ma, W. Yang, L. Chen and J. Zhao, Significant Developments in Rare-Earth-Containing Polyoxometalate Chemistry: Synthetic Strategies, Structural Diversities and Correlative Properties, CrystEngComm, 2015, 17, 8175-8197.

13 L.-L. Li, H.-Y. Han, Y.-H. Wang, H.-Q. Tan, H.-Y. Zang and Y.-G. Li, Construction of Polyoxometalates from Dynamic Lacunary Polyoxotungstate Building Blocks and Lanthanide Linkers, Dalton Trans., 2015, 44, 11429-11436.

14 M. A. AlDamen, S. Cardona-Serra, J. M. Clemente-Juan, E. Coronado, A. Gaita-Ariño, C. Martí-Gastaldo, F. Luis and O. Montero, Mononuclear Lanthanide Single Molecule Magnets Based on the Polyoxometalates $\left[\mathrm{Ln}\left(\mathrm{W}_{5} \mathrm{O}_{18}\right)_{2}\right]^{9-}$ and $\left[\mathrm{Ln}\left(\beta_{2}-\mathrm{SiW}_{11} \mathrm{O}^{39}\right)_{2}\right]^{13-} \mathrm{Ln}^{\mathrm{III}}=\mathrm{Tb}$, Dy, Ho, Er, Tm, and Yb), Inorg. Chem., 2009, 48, 3467-3479.

15 T. Yamase, Photo- and Electrochromism of Polyoxometalates and Related Materials, Chem. Rev., 1998, 98, 307-326.

16 P. Ma, F. Hu, R. Wan, Y. Huo, D. Zhang, J. Niu and J. Wang, Magnetic Double-Tartaric Bridging Mono-Lanthanide Substituted Phosphotungstates with Photochromic and Switchable Luminescence Properties, J. Mater. Chem. C, 2016, 4, 5424-5433.

17 S. Zhang, Y. Wang, J. Zhao, P. Ma, J. Wang and J. Niu, Two Types of Oxalate-Bridging Rare-Earth-Substituted KegginType Phosphotungstates $\left\{\left[\left(\alpha-\mathrm{PW}_{11} \mathrm{O}_{39}\right) \mathrm{RE}\left(\mathrm{H}_{2} \mathrm{O}\right)\right]_{2}\left(\mathrm{C}_{2} \mathrm{O}_{4}\right)\right\}^{10-}$ and $\left\{\left(\alpha-\mathrm{x}-\mathrm{PW}_{10} \mathrm{O}_{38}\right) \mathrm{RE}_{2}\left(\mathrm{C}_{2} \mathrm{O}_{4}\right)\left(\mathrm{H}_{2} \mathrm{O}\right)_{2}\right\}^{3-}$, Dalton Trans., 2012, 41, 3764-3772.

18 P. Ma, R. Wan, Y. Si, F. Hu, Y. Wang, J. Niu and J. Wang, Double-Malate Bridging Tri-Lanthanoid Cluster Encapsulated Arsenotungstates: Syntheses, Structures, Luminescence and Magnetic Properties, Dalton Trans., 2015, 44, 11514-11523.

19 R. Gupta, F. Hussain, J. N. Behera, A. M. Bossoh, I. M. Mbomekalle and P. de Oliveira, Structure, Electrochemistry and Luminescence Properties of Lanthano-Germanotungstates, RSC Adv., 2015, 5, 9975499765.

20 Y. Lu, Y. Li, E. Wang, X. Xu and Y. Ma, A New Family of Polyoxometalate Compounds Built up of Preyssler Anions and Trivalent Lanthanide Cations, Inorg. Chim. Acta, 2007, 360, 2063-2070.

21 L. Ni, F. Hussain, B. Spingler, S. Weyeneth and G. R. Patzke, Lanthanoid-Containing Open Wells-Dawson
Silicotungstates: Synthesis, Crystal Structures, and Properties, Inorg. Chem., 2011, 50, 4944-4955.

22 J. C. G. Bünzli and S. V. Eliseeva, Photophysics of Lanthanoid Coordination Compounds, Compr. Inorg. Chem. II, 2013, 8, 339-398.

23 L. Armelao, S. Quici, F. Barigelletti, G. Accorsi, G. Bottaro, M. Cavazzini and E. Tondello, Design of Luminescent Lanthanide Complexes: From Molecules to Highly Efficient Photo-Emitting Materials, Coord. Chem. Rev., 2010, 254, 487-505.

24 H. Wang, J. Li, J. Sun, Y. Wang, Z. Liang, P. Ma, D. Zhang, J. Wang and J. Niu, Synthesis, Structure, and Luminescent Properties of a Family of Lanthanide-Functionalized Peroxoniobiophosphates, Sci. Rep., 2017, 7, 10653.

25 G. Shao, Y. Li, K. Feng, F. Gan and M. Gong, Diphenylethyne Based $\beta$-Diketonate Europium(III) Complexes as Red Phosphors Applied in LED, Sens. Actuators, B, 2012, 173, 692-697.

26 S.-S. Wang and G.-Y. Yang, Recent Advances in Polyoxometalate-Catalyzed Reactions, Chem. Rev., 2015, 115, 4893-4962.

27 W. Cañón-Mancisidor, M. Zapata-Lizama, P. HermosillaIbáñez, C. Cruz, D. Venegas-Yazigi and G. Mínguez Espallargas, Hybrid Organic-Inorganic Mononuclear Lanthanoid Single Ion Magnets, Chem. Commun., 2019, 55, 14992-14995.

28 D. Zhang, C. Zhang, H. Chen, P. Ma, J. Wang and J. Niu, Structures and Properties of Dimeric Rare Earth Derivatives Based on Monovacant Keggin-Type Polyoxotungstates, Inorg. Chim. Acta, 2012, 391, 218-223.

29 J. Niu, K. Wang, H. Chen, J. Zhao, M. Pengtao, J. Wang, M. Li, Y. Bai and D. Dang, Assembly Chemistry between Lanthanide Cations and Monovacant Keggin Polyoxotungstates: Two Types of Lanthanide Substituted Phosphotungstates $\quad\left[\left\{\left(\alpha-\mathrm{PW}_{11} \mathrm{O}_{39} \mathrm{H}\right) \mathrm{Ln}\left(\mathrm{H}_{2} \mathrm{O}\right)_{3}\right\}_{2}\right]^{6-}$ and $\left[\left\{\left(\alpha-\mathrm{PW}_{11} \mathrm{O}_{39}\right) \operatorname{Ln}\left(\mathrm{H}_{2} \mathrm{O}\right)\left(\eta^{2}, \mu-1,1\right)-\mathrm{CH}_{3} \mathrm{COO}\right\}_{2}\right]^{10-}, \quad$ Cryst. Growth Des., 2009, 9, 4362-4372.

30 L. Xiao, T.-T. Zhang, Z. Liu, X. Shi, H. Zhang, L. Yin, L.-Y. Yao, C.-C. Xing and X.-B. Cui, Syntheses and Characterizations of the First N-Containing Organic Ligand Functionalized Mono-Lanthanide-Substituted Polyoxometalates, Inorg. Chem. Commun., 2018, 95, 86-89.

31 P. Ma, F. Hu, Y. Huo, D. Zhang, C. Zhang, J. Niu and J. Wang, Magnetoluminescent Bifunctional DysprosiumBased Phosphotungstates with Synthesis and Correlations between Structures and Properties, Cryst. Growth Des., 2017, 17, 1947-1956.

32 D. Casanova, J. Cirera, M. Llunell, P. Alemany, D. Avnir and S. Alvarez, Minimal Distortion Pathways in Polyhedral Rearrangements, J. Am. Chem. Soc., 2004, 126, 1755-1763.

33 D. Casanova, M. Llunell, P. Alemany and S. Álvarez, The Rich Stereochemistry of Eight-Vertex Polyhedra: A Continuous Shape Measures Study, Chem. - Eur. J., 2005, 11, 1479-1494.

34 F. J. Kettles, V. A. Milway, F. Tuna, R. Valiente, L. H. Thomas, W. Wernsdorfer, S. T. Ochsenbein and 
M. Murrie, Exchange Interactions at the Origin of Slow Relaxation of the Magnetization in $\left\{\mathrm{TbCu}_{3}\right\}$ and $\left\{\mathrm{DyCu}_{3}\right\}$ Single-Molecule Magnets, Inorg. Chem., 2014, 53, 89708978.

35 J. Zhu, C. Wang, F. Luan, T. Liu, P. Yan and G. Li, Local Coordination Geometry Perturbed $\beta$-Diketone Dysprosium Single-Ion Magnets, Inorg. Chem., 2014, 53, 8895-8901.

36 M. M. Hänninen, A. J. Mota, D. Aravena, E. Ruiz, R. Sillanpää, A. Camón, M. Evangelisti and E. Colacio, Two $\mathrm{C}_{3}$-Symmetric $\mathrm{Dy}_{3}{ }^{\mathrm{III}}$ Complexes with Triple Di- $\mu$-Methoxo$\mu$-Phenoxo Bridges, Magnetic Ground State, and SingleMolecule Magnetic Behavior, Chem. - Eur. J., 2014, 20, 8410-8420.

37 X. Li, D. Y. Wei, S. J. Huang and Y. Q. Zheng, Syntheses and Characterization of Novel Lanthanide AdamantineDicarboxylate Coordination Complexes, J. Solid State Chem., 2009, 182, 95-101.

38 X. Q. Zhang, M. S. Lin, B. Hu, W. Q. Chen, L. N. Zheng, J. Wu, Y. M. Chen, F. Y. Zhou, Y. H. Li and W. Li, Anionic Lanthanide Complexes Supported by a Pyrrole-Based Tetradentate Schiff Base Ligand: Synthesis, Structures and Catalytic Activity toward the Polymerization of $\varepsilon$-caprolactone, Polyhedron, 2012, 33, 273-279.

39 R. Faoro, F. Moglia, M. Tonelli, N. Magnani and E. Cavalli, Energy Levels and Emission Parameters of the $\mathrm{Dy}^{3+}$ Ion Doped into the $\mathrm{YPO}_{4}$ Host Lattice, J. Phys.: Condens. Matter, 2009, 21, 275501.

40 W. T. Carnall, G. L. Goodman, K. Rajnak and R. S. Rana, Systematic Analysis of the Spectra of the Lanthanides Doped into Single Crystal $\mathrm{LaF}_{3}$, J. Chem. Phys., 1989, 90, 3443-3457.

41 A. A. S. da Gama, G. F. de Sá, P. Porcher and P. Caro, Energy Levels of $\mathrm{Nd}^{3+}$ in $\mathrm{LiYF}_{4}, \mathrm{~J}$. Chem. Phys., 1981, 75, 2583-2587.

42 S. But, S. Lis, R. Van Deun, T. N. Parac-Vogt, C. GörllerWalrand and K. Binnemans, Spectroscopic Properties of Neodymium(III)-Containing Polyoxometalates in Aqueous Solution, Spectrochim. Acta, Part A, 2005, 62, 478-482.

$43 \mathrm{~W}$. F. Krupke and J. B. Gruber, Absorption and Fluorescence Spectra of $\mathrm{Er}^{3+}\left(4 f^{41}\right)$ in $\mathrm{LaF}_{3}, J$. Chem. Phys., 1963, 39, 1024-1030.

44 H. H. Caspers, H. E. Rast and J. L. Fry, Absorption, Fluorescence, and Energy Levels of $\mathrm{Ho}^{3+}$ in $\mathrm{LaF}_{3}$, J. Chem. Phys., 1970, 53, 3208-3216.

45 R. H. Linnell and A. Kaczmarczyk, Ultraviolet Spectra of [ILL] Compounds, J. Phys. Chem., 1961, 65, 11961200 .

46 G. Accorsi, A. Listorti, K. Yoosaf and N. Armaroli, 1,10Phenanthrolines: versatile building blocks for luminescent molecules, materials and metal complexes, Chem. Soc. Rev., 2009, 38, 1690-1700.

47 Z. Li, L.-D. Lin, D. Zhao, Y.-Q. Sun and S.-T. Zheng, A Series of Unprecedented Linear Mixed-Metal-Substituted Polyoxometalate Trimers: Syntheses, Structures, Luminescence, and Proton Conductivity Properties, Eur. J. Inorg. Chem., 2019, 2019, 437-441.
48 S. Cotton, Lanthanide and Actinide Chemistry, John Wiley \& Sons, Ltd, Chichester, UK, 2006.

49 R. T. Moura, A. N. Carneiro Neto, R. L. Longo and O. L. Malta, On the Calculation and Interpretation of Covalency in the Intensity Parameters of $4 f-4 f$ Transitions in $\mathrm{Eu}^{3+}$ Complexes Based on the Chemical Bond Overlap Polarizability, J. Lumin., 2016, 170, 420-430.

50 N. Vijaya, K. Upendra Kumar and C. K. Jayasankar, Spectrochim., Dy ${ }^{3+}$-Doped Zinc Fluorophosphate Glasses for White Luminescence Applications, Spectrochim. Acta, Part A, 2013, 113, 145-153.

51 K. Binnemans, Interpretation of Europium(III) Spectra, Coord. Chem. Rev., 2015, 295, 1-45.

52 L. D. Carlos, R. A. Sá Ferreira, V. de Zea Bermudez, C. Molina, L. A. Bueno and S. J. L. Ribeiro, White Light Emission of $\mathrm{Eu}^{3+}$ Based Hybrid Xerogels, Phys. Rev. B: Condens. Matter Mater. Phys., 1999, 60, 10042-10053.

53 F. A. de Jesus, S. T. S. Santos, J. M. A. Caiut and V. H. V. Sarmento, Effects of Thermal Treatment on the Structure and Luminescent Properties of $\mathrm{Eu}^{3+}$ Doped $\mathrm{SiO}_{2}$-PMMA Hybrid Nanocomposites Prepared by a SolGel Process, J. Lumin., 2016, 170, 588-593.

54 B. R. Judd, Optical Absorption Intensities of Rare-Earth Ions, Phys. Rev., 1962, 127, 750-761.

55 G. S. Ofelt, Intensities of Crystal Spectra of Rare-Earth Ions, J. Chem. Phys., 1962, 37, 511-520.

56 W. T. Carnall, P. R. Fields and B. G. Wybourne, Spectral Intensities of the Trivalent Lanthanides and Actinides in Solution. I. $\mathrm{Pr}^{3+}, \mathrm{Nd}^{3+}, \mathrm{Er}^{3+}, \mathrm{Tm}^{3+}$, and $\mathrm{Yb}^{3+}$, J. Chem. Phys., 1965, 42, 3797-3806.

57 K. Binnemans, K. Van Herck and C. Görller-Walrand, Influence of Dipicolinate Ligands on the Spectroscopic Properties of Europium(III) in Solution, Chem. Phys. Lett., 1997, 266, 297-302.

58 A. Aebischer, F. Gumy and J.-C. G. Bünzli, Intrinsic Quantum Yields and Radiative Lifetimes of Lanthanide Tris(Dipicolinates), Phys. Chem. Chem. Phys., 2009, 11, 1346-1353.

59 J. C. G. Bünzli, A. S. Chauvin, H. K. Kim, E. Deiters and S. V. Eliseeva, Lanthanide Luminescence Efficiency in Eight- and Nine-Coordinate Complexes: Role of the Radiative Lifetime, Coord. Chem. Rev., 2010, 254, 26232633.

60 M. Latva, H. Takalo, V.-M. Mukkala, C. Matachescu, J. C. Rodríguez-Ubis and J. Kankare, Correlation between the Lowest Triplet State Energy Level of the Ligand and Lanthanide(III) Luminescence Quantum Yield, J. Lumin., 1997, 75, 149-169.

61 X.-P. Yang, B.-S. Kang, W.-K. Wong, C.-Y. Su and H.-Q. Liu, Syntheses, Crystal Structures, and Luminescent Properties of Lanthanide Complexes with Tripodal Ligands Bearing Benzimidazole and Pyridine Groups, Inorg. Chem., 2003, 42, 169-179.

62 P. Xiao, P. Wang, R. Q. Fan, X. Du, W. Chen, H. J. Zhang, Y. Song and Y. L. Yang, Lanthanide MOFs Constructed Based on a Difunctional Ligand with Bimodal Emission 
and $\mathrm{Eu}^{3+}$ Doped $\mathrm{Dy}^{3+}$ Materials: White Emission and Color Tuning, RSC Adv., 2016, 6, 83091-83100.

63 F. J. Steemers, W. Verboom, D. N. Reinhoudt, E. B. van der Tol and J. W. Verhoeven, New Sensitizer-Modified Calix[4] Arenes Enabling Near-UV Excitation of Complexed Luminescent Lanthanide Ions, J. Am. Chem. Soc., 1995, 117, 9408-9414.

64 H. Wu, B. Yan, R. Liang, V. Singh, P. Ma, J. Wang and J. Niu, An organic chromophore -modified samarium- containing polyoxometalate: excitation-dependent color tunable behavior from the organic chromophores to the lanthanide ion, Dalton Trans., 2020, 49, 388-394.

65 C. Ritchie, V. Baslon, E. G. Moore, C. Reber and C. Boskovic, Sensitization of Lanthanoid Luminescence by Organic and Inorganic Ligands in Lanthanoid-OrganicPolyoxometalates, Inorg. Chem., 2012, 51, 1142-1151.

66 J. R. Lakowicz, Principles of Fluorescence Spectroscopy, Springer US, Boston, MA, 2006.

67 J. Priya, N. K. Gondia, A. K. Kunti and S. K. Sharma, Pure White Light Emitting Tetrakis $\beta$-Diketonate Dysprosium Complexes for OLED Applications, ECS J. Solid State Sci. Technol., 2016, 5, R166-R171.

68 T. Yamase, T. Kobayashi, M. Sugeta and H. Naruke, Europium(III) Luminescence and Intramolecular Energy Transfer Studies of Polyoxometalloeuropates, J. Phys. Chem. A, 1997, 101, 5046-5053.

69 H. Wu, B. Yan, H. Li, V. Singh, P. Ma, J. Niu and J. Wang, Enhanced Photostability Luminescent Properties of $\mathrm{Er}^{3+}$ Doped Near-White-Emitting $\operatorname{Dy}_{\mathrm{x}} \operatorname{Er}_{(1-\mathrm{x})}$-POM Derivatives, Inorg. Chem., 2018, 57, 7665-7675.

70 T. Yamase, in Handbook on the Physics and Chemistry of Rare Earths, Elesvier B.V., 1st edn, 2009, vol. 39, pp. 297-356.

71 S. Comby, D. Imbert, A.-S. Chauvin, J.-C. G. Bünzli, L. J. Charbonnière and R. F. Ziessel, Influence of Anionic Functions on the Coordination and Photophysical Properties of Lanthanide(III) Complexes with Tridentate Bipyridines, Inorg. Chem., 2004, 43, 7369-7379.

72 C. Wyman, P.-P. Sloan and P. Shirley, Simple Analytic Approximations to the CIE XYZ Color Matching Functions, J. Comput. Graph. Tech., 2013, 2, 1-11.

73 P. D. Bhoyar, G. B. Nair and S. J. Dhoble, Photoluminescence Properties of Different Luminescent Ions $\left(\mathrm{Ce}^{3+}, \mathrm{Eu}^{3+}, \mathrm{Eu}^{2+}, \mathrm{Dy}^{3+}, \mathrm{Cu}^{+}\right)$in $\mathrm{K}_{2} \mathrm{LaCl}_{5}$ Host Matrix, Optik, 2017, 134, 33-44.
74 W.-F. Zhao, C. Zou, L.-X. Shi, J.-C. Yu, G.-D. Qian and C.-D. Wu, Synthesis of Diamondoid LanthanidePolyoxometalate Solids as Tunable Photoluminescent Materials, Dalton Trans., 2012, 41, 10091-10096.

75 H. L. Li, Z. L. Wang, S. J. Xu and J. H. Hao, Improved Performance of Spherical $\mathrm{BaWO}_{4}: \mathrm{Tb}^{3+}$ Phosphors for FieldEmission Displays, J. Electrochem. Soc., 2009, 156, J112J116.

76 C. S. McCamy, Correlated Color Temperature as an Explicit Function of Chromaticity Coordinates, Color Res. Appl., 1992, 17, 142-144.

77 W. Salomon, A. Dolbecq, C. Roch-Marchal, G. Paille, R. Dessapt, P. Mialane and H. Serier-Brault, Multifunctional Dual-Luminescent Polyoxometalate@Metal-Organic_ Framework EuW10@UiO-67 Composite as Chemical Probe and Temperature Sensor, Front. Chem., 2018, 6, 425.

78 Q. Xu, Z. Li, Y. Wang and H. Li, Temperature-dependent luminescence properties of lanthanide(III) $\beta$-diketonate complex-doped LAPONITE®, Photochem. Photobiol. Sci., 2016, 15, 405-411.

79 E. Radkov and R. H. Beer, High Yield Synthesis of MixedMetal Keggin Polyoxoanions in Non-Aqueous Solvents: Preparation of $\left(\mathrm{n}-\mathrm{Bu}_{4} \mathrm{~N}\right)_{4}\left[\mathrm{PMW}_{11} \mathrm{O}_{40}\right](\mathrm{M}=\mathrm{V}, \mathrm{Nb}, \mathrm{Ta})$, Polyhedron, 1995, 14, 2139-2143.

80 SAINTPLUS, Version 6.02, Brucker AXS, Madison, WI, USA, 1999.

81 G. M. Sheldrick, Crystal Structure Refinement with SHELXL, Acta Crystallogr., Sect. C: Struct. Chem., 2015, 71, 3-8.

82 G. M. Sheldrick, SHELXT - Integrated Space-Group and Crystal-Structure Determination, Acta Crystallogr., Sect. A: Found. Adv., 2015, 71, 3-8.

83 K. Brandenburg, Diamond, Version 3.2k, Cryst. Impact GbR, Bonn, Ger, 2014.

84 M. S. Wrighton, Technique for the Determination of Absolute Emission Quantum Yields of Powdered Samples. D. S. Ginley and D. L. Morse, J. Phys. Chem., 1974, 78, 2229-2233.

85 J. A. Do Nascimento Neto, A. K. S. M. Valdo, C. C. da Silva, F. F. Guimarães, L. H. K. Queiroz Júnior, L. J. Q. Maia, R. C. de Santana and F. T. Martins, Blue Light Emitting Cadmium Coordination Polymer with 75.4\% External Quantum Efficiency, J. Am. Chem. Soc., 2019, 141, 34003403. 